\title{
Stronger proteasomal inhibition and higher CHOP induction are responsible for more effective induction of paraptosis by dimethoxycurcumin than curcumin
}

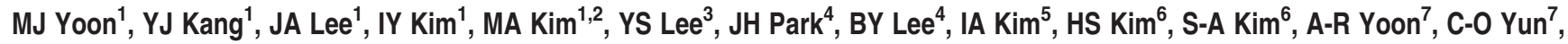 \\ $\mathrm{E}-\mathrm{Y} \mathrm{Kim}{ }^{8}, \mathrm{KLee}^{8}$ and KS Choi ${ }^{\star * 1,3}$
}

Although curcumin suppresses the growth of a variety of cancer cells, its poor absorption and low systemic bioavailability have limited its translation into clinics as an anticancer agent. In this study, we show that dimethoxycurcumin (DMC), a methylated, more stable analog of curcumin, is significantly more potent than curcumin in inducing cell death and reducing the clonogenicity of malignant breast cancer cells. Furthermore, DMC reduces the tumor growth of xenografted MDA-MB $435 \mathrm{~S}$ cells more strongly than curcumin. We found that DMC induces paraptosis accompanied by excessive dilation of mitochondria and the endoplasmic reticulum (ER); this is similar to curcumin, but a much lower concentration of DMC is required to induce this process. DMC inhibits the proteasomal activity more strongly than curcumin, possibly causing severe ER stress and contributing to the observed dilation. DMC treatment upregulates the protein levels of CCAAT-enhancer-binding protein homologous protein (CHOP) and Noxa, and the small interfering RNA-mediated suppression of CHOP, but not Noxa, markedly attenuates DMCinduced ER dilation and cell death. Interestingly, DMC does not affect the viability, proteasomal activity or CHOP protein levels of human mammary epithelial cells, suggesting that DMC effectively induces paraptosis selectively in breast cancer cells, while sparing normal cells. Taken together, these results suggest that DMC triggers a stronger proteasome inhibition and higher induction of CHOP compared with curcumin, giving it more potent anticancer effects on malignant breast cancer cells.

Cell Death and Disease (2014) 5, e1112; doi:10.1038/cddis.2014.85; published online 13 March 2014

Subject Category: Cancer

Breast cancer remains a major cause of morbidity and mortality worldwide. ${ }^{1}$ The incidence of breast cancer has been increasing over the past four decades and there are relatively few effective therapies for advanced-stage disease. Despite improvement in treatment options, the mortality of breast cancer patients has remained stable. Thus, many scientists are currently seeking new anticancer agents with better efficiency and fewer side effects.

Curcumin has demonstrated selective killing of various cancer cell types, while sparing normal cells. ${ }^{2-4}$ Despite the cancer-selective cytotoxic effects of curcumin, however, its clinical use has been limited by poor systemic bioavailability, poor absorption, rapid metabolism and conjugation in the gastrointestinal tract. ${ }^{5}$ In order to overcome these issues, new improved analogs of curcumin have been synthesized and tested. ${ }^{6-8}$ Dimethoxycurcumin (DMC) is a methylated analog, in which the phenolic-OH groups of curcumin have been replaced with methoxy groups. ${ }^{9,10}$ Tamvakopoulos et al. ${ }^{11}$ showed that DMC is more stable in cultured cells and in vivo, and has increased bioavailability compared with curcumin. In addition, DMC more potently induced apoptosis in HCT116 human colon cancer cells ${ }^{11}$ and Caki renal cancer cells, ${ }^{12}$ but was less toxic in lymphocytes, ${ }^{10}$ compared with curcumin. However, the mechanisms underlying the anticancer effects of DMC have not been fully explored.

Here, we show for the first time that DMC demonstrates more potent anticancer effects than curcumin on malignant breast cancer cells in vitro and in vivo, while sparing normal breast cells. We further report that DMC induces paraptosis at much lower doses than curcumin. Sperandio et al. ${ }^{13}$ first introduced the concept of 'paraptosis' as an alternative, nonapoptotic form of programmed cell death. This mode of

\footnotetext{
${ }^{1}$ Department of Biochemistry, Department of Biomedical Sciences, Ajou University School of Medicine, Suwon, Korea; ${ }^{2}$ Cancer Cell and Molecular Biology Branch, Division of Cancer Biology, Research Institute, National Cancer Center, Goyang, Korea; ${ }^{3}$ Department of Biomedical Sciences, Genomic Instability Research Center, Ajou University School of Medicine, Suwon, Korea; ${ }^{4}$ Department of Molecular Science and Technology, Ajou University, Suwon, Korea; ${ }^{5}$ Department of Radiation Oncology, Seoul National University Bundang Hospital, Seongnam, Korea; ${ }^{6}$ College of Pharmacy, Institute of Pharmaceutical Research and Development, Wonkwang University, Iksan, Korea; ${ }^{7}$ Department of Bioengineering, College of Engineering, Hanyang University, Seoul, Korea and ${ }^{8}$ College of Pharmacy, Korea University, Sejong, Korea

${ }^{*}$ Corresponding author: KS Choi, Department of Biochemistry, Department of Biomedical Sciences, Ajou University School of Medicine, San 5 Wonchon-dong, Youngtong-gu, Suwon, Kyungki-do 442-749, Korea. Tel: + 8231219 4552; Fax: + 8231219 4530; E-mail: kschoi@ajou.ac.kr

Keywords: dimethoxycurcumin; curcumin; paraptosis; malignant breast cancer cells; proteasomal inhibition

Abbreviations: DMC, dimethoxycurcumin; ER, endoplasmic reticulum; CHOP, CCAAT-enhancer-binding protein homologous protein; ATF4, activating transcription factor 4; COX IV, cytochrome oxidase subunit IV; PDI, protein disulfide-isomerase; MAP kinase, mitogen-activated protein kinase; Alix, ALG-2-interacting protein X; ROS, reactive oxygen species; PGPH-like, peptidylglutamyl peptide hydrolyzing-like; HBSS, Hank's balanced salt solution; 3-MA, 3-methyladenine; CuDIPS, copper[II]diisopropyl salicylate; MnTBAP, Mn(III)tetrakis (4-benzoic acid) porphyrin chloride; CHX, cycloheximide; L-JNKI, L-JNK Inhibitor 1; siRNA, small interfering RNA; HMECs, human mammary epithelial cells; PI, proteasome inhibitor Received 13.9.13; revised 20.1.14; accepted 05.2.14; Edited by E Baehrecke
} 
cell death lacks the characteristic apoptotic features (e.g., nuclear fragmentation, chromatin condensation and the formation of apoptotic bodies) and does not respond to the typical inhibitors of apoptosis (e.g., caspase inhibitors and $\mathrm{Bcl}-\mathrm{xL}$ ). Observations that paraptosis can be inhibited by cycloheximide $(\mathrm{CHX})$ indicate that the process requires protein synthesis, ${ }^{3,13-15}$ thereby distinguishing it from necrosis. ${ }^{13}$ Paraptosis is also insensitive to various autophagy inhibitors. ${ }^{3,15}$ Ultrastructural observation of cells undergoing paraptosis has identified cytoplasmic vacuolation as being characteristic of this process; the mitochondria and endoplasmic reticulum (ER) first swell, and then fuse to create large vacuoles. ${ }^{3}$ Paraptosis appears to occur during the development of the nervous system, as well as in some cases of neurodegeneration. ${ }^{13,16}$ Paraptotic cells in brain tissues were observed to be filled with small and large vacuoles. ${ }^{17}$ In addition, various stimuli, including paclitaxel, ${ }^{18}$ curcumin $^{3,19}$ and ophiobolin $A,{ }^{20}$ reportedly induce paraptosis or paraptosis-like cell death in resistant malignant cancer cells, suggesting that paraptosis may provide a strategy for overcoming innate and acquired resistance to the current proapoptotic anticancer therapies. However, the molecular basis of paraptosis is still poorly defined, and additional evidence is required to confirm the authentic biochemical markers of this process. ALG-2-interacting protein X (Alix) has been identified as an inhibitor of paraptosis. . $14,21-23$ In addition, mitogenactivated protein (MAP) kinase activation has been associated with paraptosis induced by insulin-like growth factor I receptor, ${ }^{14}$ 1-nitropyrene, ${ }^{23}$ paclitaxel, ${ }^{24}$ curcumin, ${ }^{3,19}$ celastrol $^{25}$ and yessotoxin, $^{26}$ although the importance of the respective MAP kinase differs depending on the stimulus. $3,14,20,23-26$ We recently showed that proteasomal dysfunction and the generation of mitochondrial superoxide are critical for the curcumin-induced dilation of mitochondria and/or the ER and subsequent paraptotic cell death in breast cancer cells. ${ }^{3}$ In this study, we provide evidence suggesting that the ability of DMC to effectively induce paraptosis via potent proteasomal inhibition and CCAAT-enhancer-binding protein homologous protein (CHOP) upregulation may be responsible for its improved anticancer effects on malignant breast cancer cells, compared with curcumin.

\section{Results}

DMC demonstrates more potent anticancer effects on breast cancer cells in vitro and in vivo than curcumin. To evaluate the anticancer activity of DMC on various breast cancer cells, we first compared its cytotoxic effects with those of curcumin (Figure 1a). We found that DMC treatment more potently induced cell death in various breast cancer cell lines (Figure $1 \mathrm{~b}$ ). Although the $\mathrm{IC}_{50}$ values for curcumin were 151.95, 76.27, 37.48 and $34.75 \mu \mathrm{M}$ for T-47D, MCF-7, MDAMB 435S and MDA-MB 231 cells, respectively, those of DMC were $21.75,23.62,20.05$ and $22.44 \mu \mathrm{M}$, respectively. We then compared the effects of curcumin and DMC on the longterm survival and found that treatment with $10 \mu \mathrm{M} \mathrm{DMC}$ for $12 \mathrm{~h}$ completely blocked the clonogenicity of MDA-MB $435 \mathrm{~S}$ cells, whereas at least $30 \mu \mathrm{M}$ curcumin was required to achieve the same effect (Figure 1c). Furthermore, $10 \mu \mathrm{M}$ DMC required a much shorter incubation time than $10 \mu \mathrm{M}$ curcumin to inhibit the clonogenicity of these cells. These results show that the anticancer effects of DMC on long-term survival appear to be greater than that on in vitro cytotoxicity to breast cancer cells. Similar results were obtained in MDAMB 231 cells (Supplementary Figure 1). Next, we examined the anticancer effects of curcumin and DMC in vivo. Nude mice were xenografted with MDA-MB $435 S$ cells, injected with curcumin or DMC at two doses $(25$ and $50 \mathrm{mg} / \mathrm{kg}$ ) at intervals of 2 days for 20 days and tumor sizes were estimated. Both curcumin and DMC dose-dependently reduced the tumor sizes, but the tumor-reducing effect of DMC at $25 \mathrm{mg} / \mathrm{kg}$ was greater than that of curcumin at $50 \mathrm{mg} / \mathrm{kg}$ (Figure 1d), suggesting that DMC demonstrates a more potent in vivo anticancer effect than curcumin. To further confirm the in vivo anticancer effects of curcumin or DMC, we utilized bioluminescence imaging, which is a more sensitive measure of tumor growth than caliper measurement. Nude mice were injected with MDA-MB $435 \mathrm{~S}$ cells engineered to express luciferase (MDA-MB 435S/Luc). Once a palpable mass was detectable (about 2 weeks), mice were subjected to intraperitoneal injections of vehicle, $50 \mathrm{mg} / \mathrm{kg}$ curcumin or DMC every 2 days for 20 days. Bioluminescent imaging analysis showed that DMC more effectively reduced the luciferase activity in tumors compared with curcumin, indicating again that DMC inhibited tumor growth more strongly than curcumin (Figure 1e). Collectively, these results indicate that DMC demonstrates more potent anticancer effects than curcumin when tested on breast cancer cells in vitro and in vivo.

DMC effectively kills malignant breast cancer cells via induction of paraptosis. Investigation of the cellular morphologies showed that marked vacuolation commonly preceded cell death in DMC-treated MDA-MB 435S, MDAMB 231, MCF-7 and T-47D cells (Figure 2a). We did not observe the morphological features of apoptosis, including cellular shrinkage, cytoplasmic blebbing and apoptotic bodies, in these DMC-treated breast cancer cells.

\footnotetext{
Figure 1 DMC demonstrates more potent anticancer effects than curcumin in vitro and in vivo. (a) Chemical structures of curcumin and DMC. (b) Effects of curcumin and DMC on the viability of various breast cancer cells in vitro. Cells were treated with curcumin or DMC at the indicated concentrations for $24 \mathrm{~h}$ and their cellular viabilities were assessed using calcein-AM and EthD-1. (c) Dose- and time-dependent effects of curcumin and DMC on the long-term survival of MDA-MB 435S cells. MDA-MB 435S cells seeded on six-well plates were treated with DMC or curcumin at the indicated concentrations for $12 \mathrm{~h}$ and then media were replaced with drug-free media. Following the subsequent incubation for 9 days, cells were stained with $0.5 \%$ crystal violet. Representative dishes after clonogenic assay are shown and colony-forming units were enumerated and expressed as the percentages of control cells. (d) Effects of curcumin and DMC on the tumor sizes of the nude mice with xenograft. Athymic nude mice of 6-8 weeks old were xenografted with MDA-MB $435 \mathrm{~S}$ cells and injected with vehicle, $25 \mathrm{mg} / \mathrm{kg}$ curcumin, $50 \mathrm{mg} / \mathrm{kg}$ curcumin, $25 \mathrm{mg} / \mathrm{kg}$ DMC or $50 \mathrm{mg} / \mathrm{kg}$ DMC as described in Materials and Methods section. Tumor sizes were measured every 2 days after the beginning of vehicle (filter-sterilized PBS containing $0.25 \%$ DMSO), curcumin or DMC injection. (e) MDA-MB 435S/Luc cells were injected into the left thigh of athymic mice. Xenografted mice were treated with vehicle, $50 \mathrm{mg} / \mathrm{kg}$ curcumin or $50 \mathrm{mg} / \mathrm{kg}$ DMC as described in Materials and Methods section. Tumor progression was evaluated by bioluminescent imaging at day 20 after the beginning of the indicated treatments
} 
a<smiles>COc1cc(/C=C/C(=O)CC(=O)/C=C/c2ccc(O)c(OC)c2)ccc1O</smiles><smiles>COc1ccc(/C=C/C(=O)CC(=O)/C=C/c2ccc(OC)c(OC)c2)cc1OC</smiles>

b

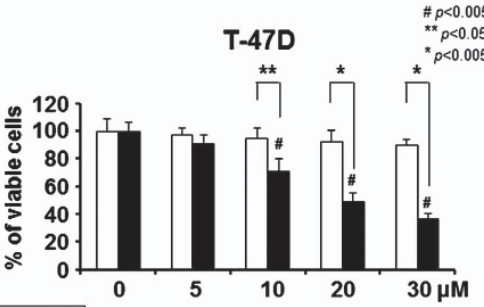

MCF-7
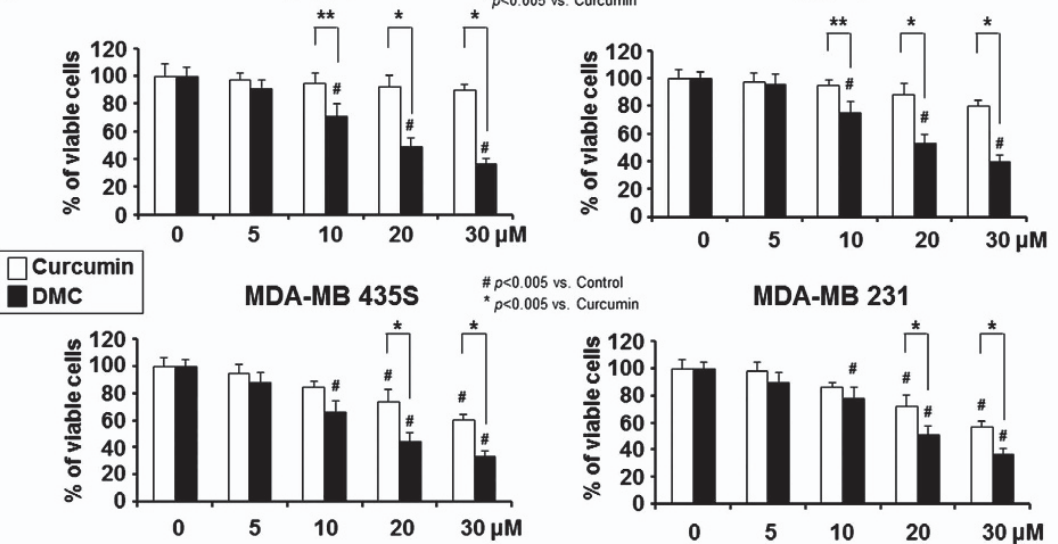

C

DMC
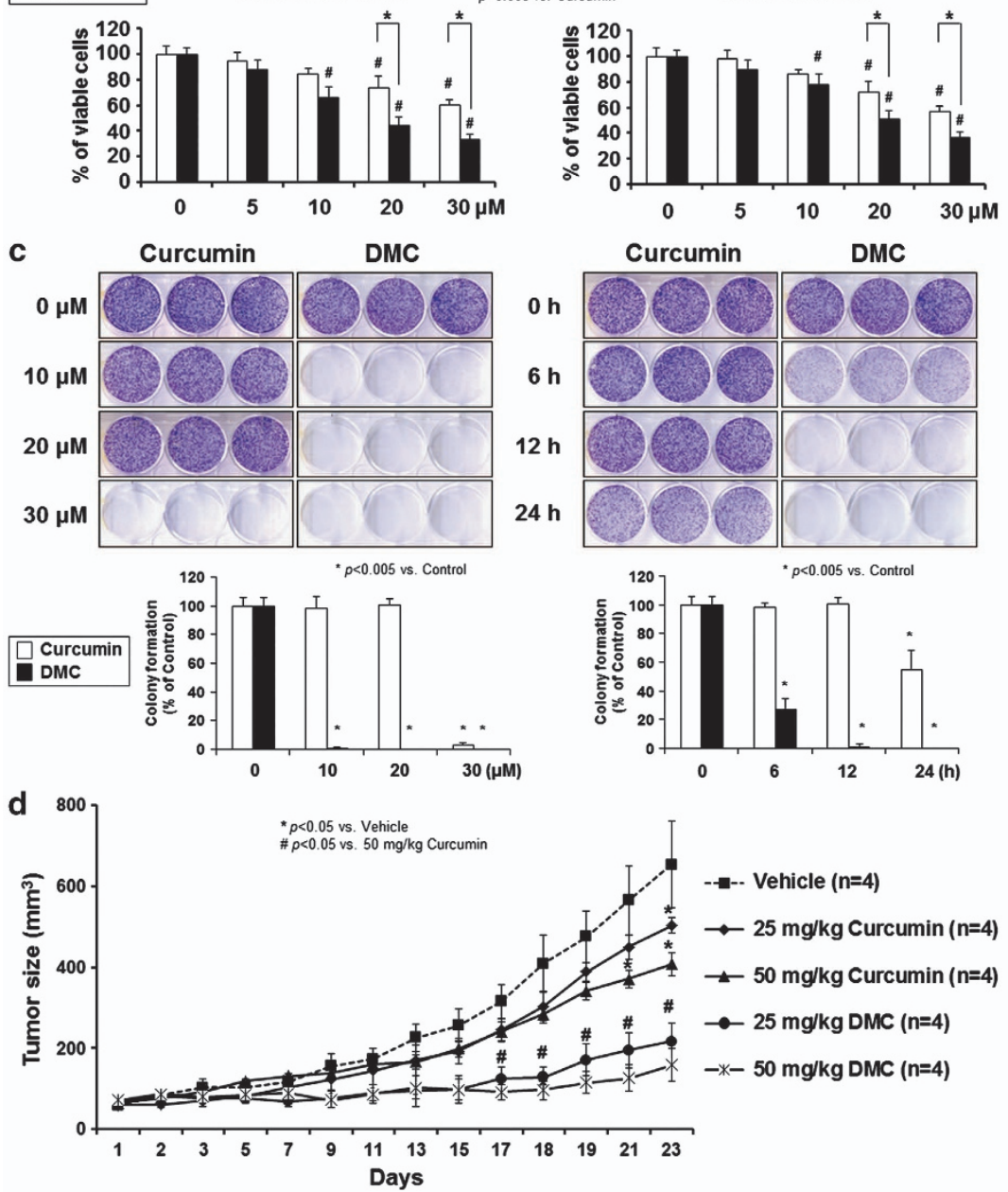

e
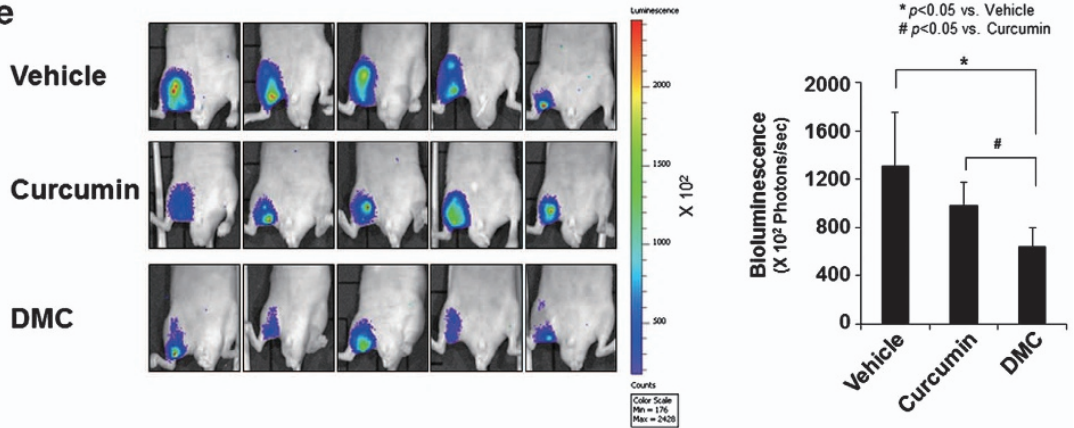
Furthermore, the DMC-induced cell death of MDA-MB 435S cells was not inhibited by various caspase-specific inhibitors, and caspase-8, -9 and -3 were not noticeably processed by DMC (Supplementary Figure 2), suggesting that apoptosis is not involved in the DMC-induced death of these breast cancer cells. In addition, hematoxylin and eoxin staining also showed severe cellular vacuolation (without noticeable nuclear condensation or fragmentation) in the sections of MDA-MB 435S xenografts treated with $25 \mathrm{mg} / \mathrm{kg}$ DMC at intervals of 2 days for 20 days, compared with those treated with vehicle (Figure 2b). When we examined whether autophagy was involved in DMC-induced cell death,

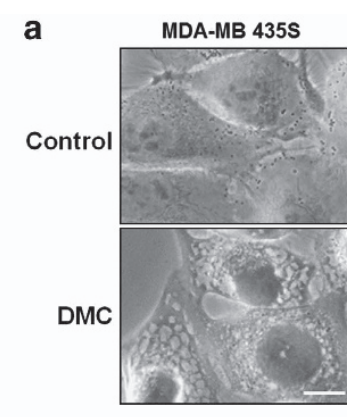

b

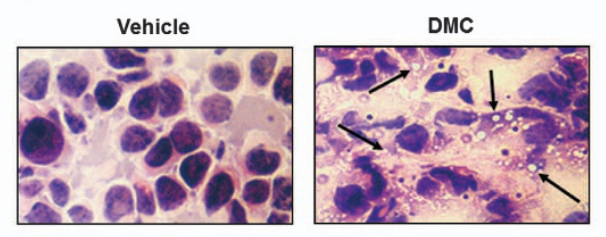

\section{MDA-MB 231}

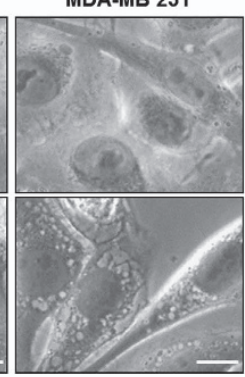

MCF-7

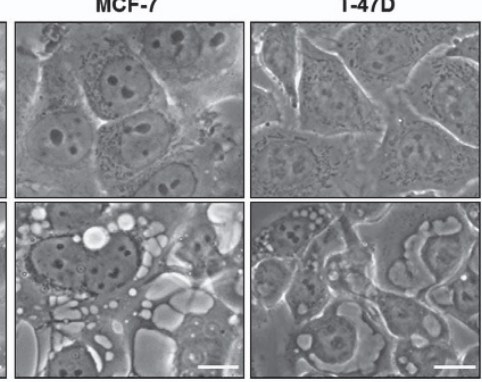

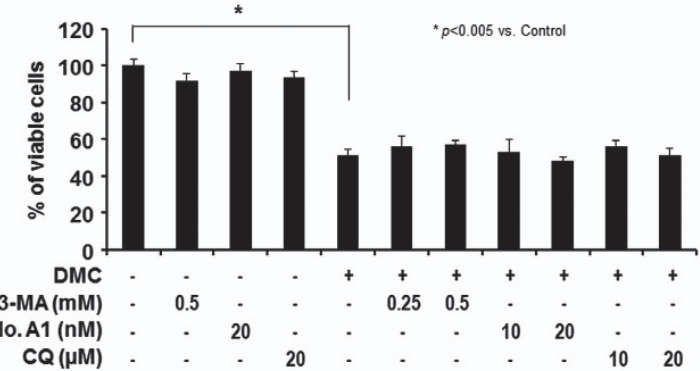

d

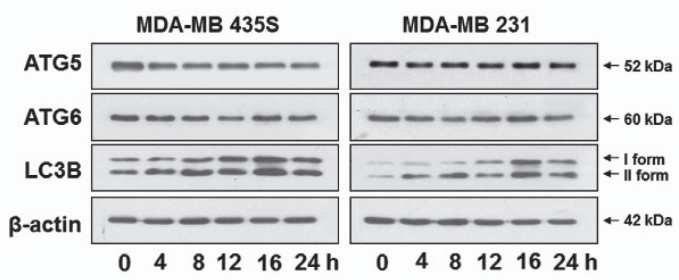

e SIRNA Control LC3B

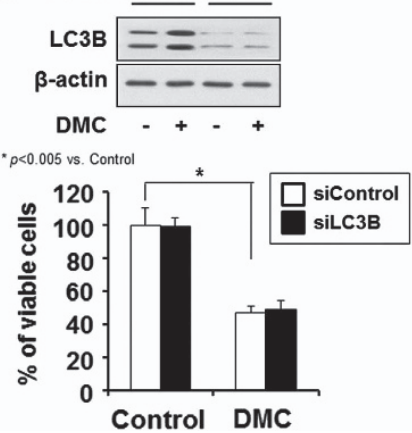

f

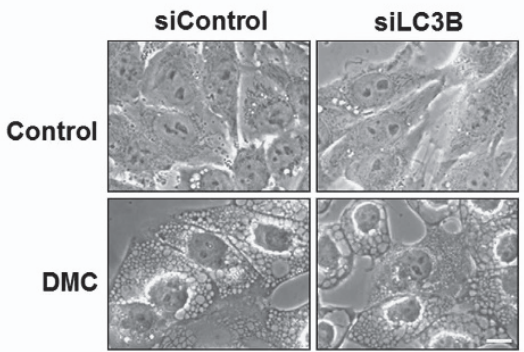

Figure 2 Dilation of mitochondria and ER precedes DMC-induced cell death in breast cancer cells. (a) Cells were treated with $20 \mu \mathrm{M} \mathrm{DMC}$ for $12 \mathrm{~h}$ and observed under a phase contrast microscope. Bars, $20 \mu \mathrm{m}$. (b) Hematoxylin and eosin-stained sections of MDA-MB 435S xenografts treated with vehicle or $25 \mathrm{mg} / \mathrm{kg}$ DMC at intervals of 2 days for 20 days. Vacuoles are indicated by arrows. (c) MDA-MB 435S cells were pre-treated with the indicated specific inhibitors of autophagy (3-MA; bafiolmycin A1 (Bafilo. A1); $\mathrm{CQ}$ ) and further treated with $20 \mu \mathrm{M} \mathrm{DMC}$ for $24 \mathrm{~h}$. Cell viability was assessed using calcein-AM and EthD-1. (d) MDA-MB $435 S$ or MDA-MB 231 cells were treated with $20 \mu \mathrm{M}$ DMC for the indicated time points and western blotting of autophagy-related proteins were performed. Western blotting of $\beta$-actin served as the loading control of protein samples. (e) MDA-MB 435S cells were transfected with LC3 siRNA and further treated with or without $20 \mu \mathrm{M} \mathrm{DMC}$ for $24 \mathrm{~h}$. Knockdown of LC3 was confirmed by western blotting using anti-LC3 antibody. Western blotting of $\beta$-actin was served as a loading control (upper panel). Cellular viability was assessed using calcein-AM and EthD-1 (lower panel). (f) MDA-MB 435S cells were transfected with LC3 siRNA and further treated with or without $20 \mu \mathrm{M} \mathrm{DMC}$ for $16 \mathrm{~h}$. Cellular morphologies were observed under a phase contrast microscope. Bar, $20 \mu \mathrm{m}$

Figure 3 DMC induces the dilation of mitochondria and the ER. (a) MDA-MB 435S sublines (YFP-Mito/435S or YFP-ER/435S) expressing the fluorescence selectively in mitochondria or the ER were treated with $20 \mu \mathrm{M}$ DMC for the indicated time points and observed under the fluorescent and phase contrast microscope. Bars, $20 \mu \mathrm{m}$. (b) The average widths of the vacuoles originated from mitochondria or the ER were measured in YFP-Mito cells or YFP-ER cells treated with $20 \mu \mathrm{M}$ DMC for the indicated time points using AxioVision Rel. 4.8 software (Zeiss). Marked increase in the width of the ER-derived vacuoles was observed following treatment with $20 \mu \mathrm{m} \mathrm{DMC.} \mathrm{Results} \mathrm{were} \mathrm{repeated}$ in three other independent experiments. In each experiment, 50 cells were scored. Bar, $20 \mu \mathrm{m}$. (c) MDA-MB 435S cells were untreated or treated with $20 \mu \mathrm{m}$ DMC for $16 \mathrm{~h}$, fixed and subjected for immunocytochemistry of COX IV and PDI. Representative pictures of cells are shown. Bars, $20 \mu \mathrm{m}$. (d) MDA-MB 435S cells were treated with $20 \mu \mathrm{M}$ DMC for the indicated durations and electron microscopy was performed as described in the Materials and Methods section. White arrows, megamitochondria; black arrows, swollen and fused ER. Bars, $2 \mu \mathrm{m}$. (e) MDA-MB 435S cells were treated with the indicated concentrations of DMC or curcumin for $16 \mathrm{~h}$. Representative pictures of cells are shown. Bar, $20 \mu \mathrm{m}$ 

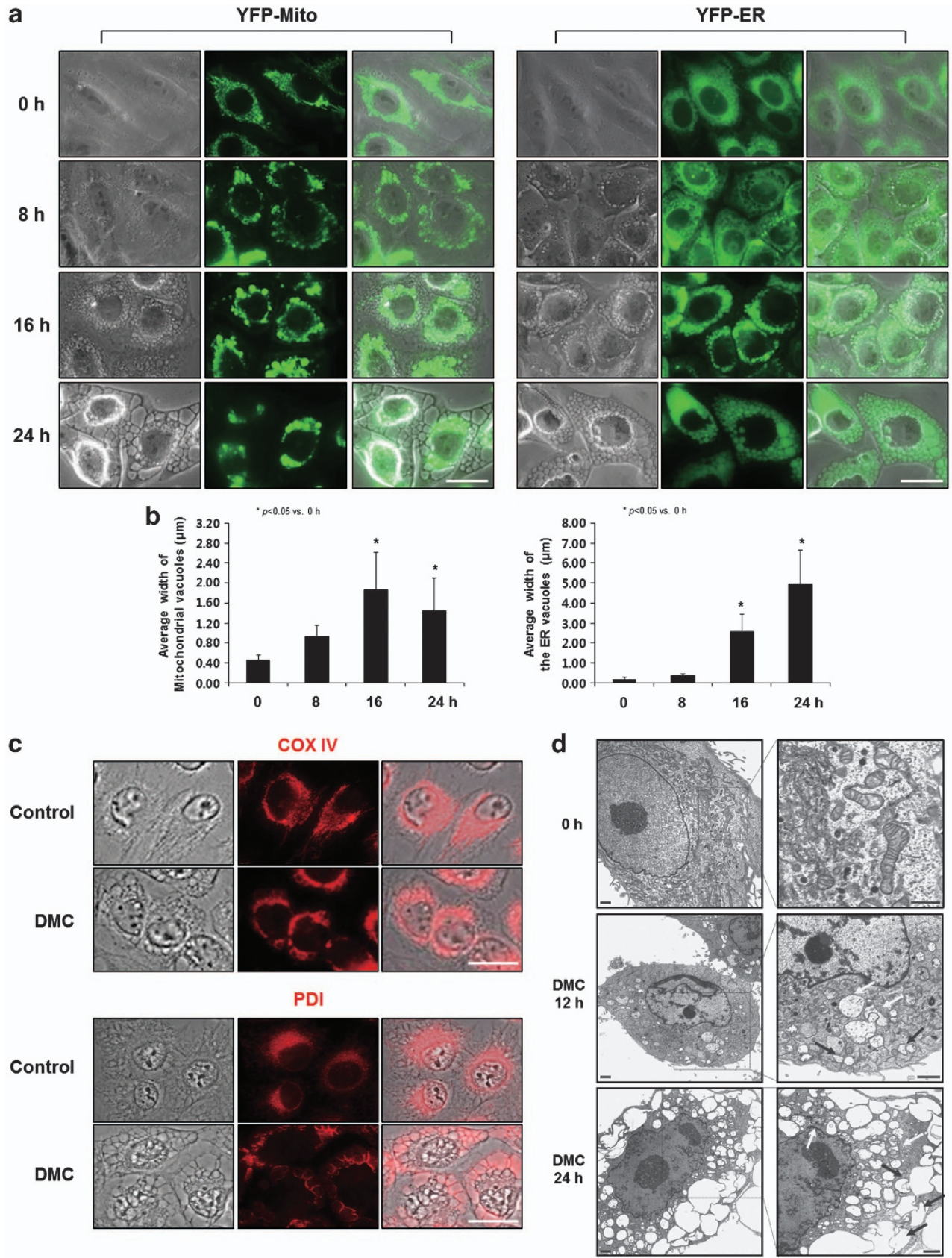

e

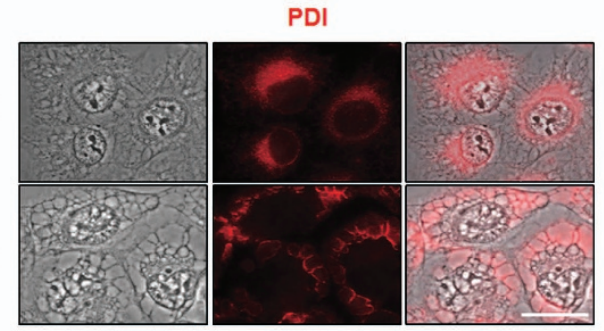

$20 \mu \mathrm{M}$

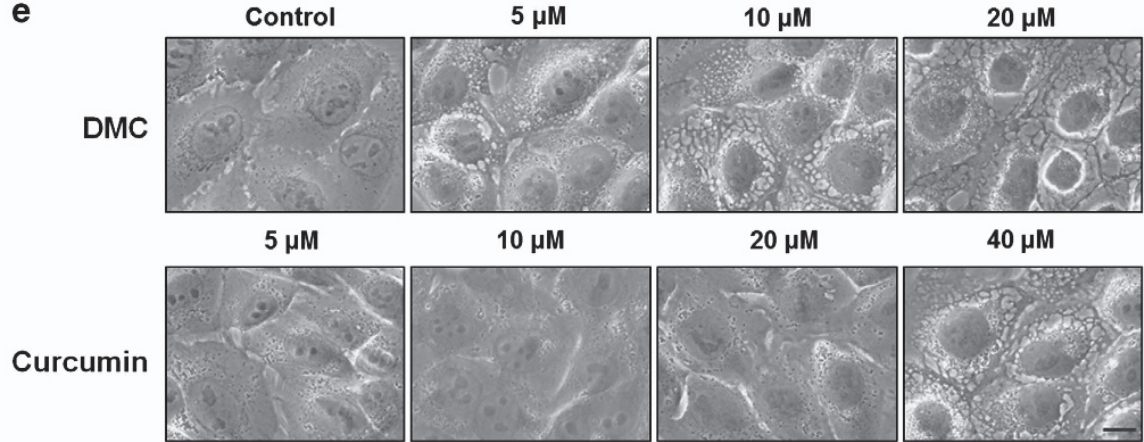


DMC-induced cell death was not affected by 3-methyladenine (3-MA), bafilomycin A1 and chloroquine (CQ) (Figure 2c). However, interestingly, both I and II forms of LC3, but not ATG5 and ATG6, were upregulated by DMC (Figure 2d). As LC3 was critically involved in cytoplasmic vacuolation and cell death induced by $15 \mathrm{~d}-\mathrm{PGJ} 2,{ }^{27}$ we next tested whether upregulation of LC3 has a role in DMC-induced vacuolation and subsequent cell death. We found that neither DMCinduced cell death nor vacuolation was affected by knockdown of LC3 (Figures $2 e$ and f). Thus, our results show that autophagy and LC3 are not involved in the DMC-induced cell death of breast cancer cells.

Next, we tested whether the vacuoles induced by DMC treatment may originate from mitochondria and/or the ER. When we used MDA-MB 435S sublines expressing fluorescence selectively in mitochondria (YFP-Mito cells) or the ER (YFP-ER cells), we found that at $16 \mathrm{~h}$ of $20 \mu \mathrm{M}$ DMC treatment, dilation of mitochondria was noted around the nuclei and a lot of small ER-derived vacuoles were also observed at the cellular periphery (Figure $3 a$ ). These vacuoles originating from both mitochondria and the ER were progressively enlarged by the prolonged exposure to DMC. When we quantitatively measured the sizes of these vacuoles, the average width of the mitochondria-derived vacuoles and that of the ER-derived vacuoles were 1.42 and $4.93 \mu \mathrm{m}$, respectively, at $24 \mathrm{~h}$ of DMC treatment (Figure $3 \mathrm{~b}$ ). Immunocytochemistry of cytochrome oxidase subunit IV (COX IV), a mitochondrial protein, and protein disulfide-isomerase (PDI), an ER resident protein, showed that COX IV expression in MDA-MB 435S cells treated with $\mathrm{DMC}$ for $16 \mathrm{~h}$ was observed at the boundary of vacuoles around the nuclei, whereas PDI expression was mainly detected at the boundary of enlarged vacuoles at the cellular periphery (Figure $3 \mathrm{c}$ ). When we performed electron microscopy, most of the mitochondria had disrupted cristae and they were swollen in MDA-MB 435 S cells treated with $20 \mu \mathrm{M}$ DMC for $12 \mathrm{~h}$ (Figure 3d). Furthermore, megamitochondria arising from fusion among swollen mitochondria were frequently observed at this time. In cells treated with $20 \mu \mathrm{M}$ DMC for $24 \mathrm{~h}$, there were numerous fusions between swollen sections of the ER and almost the entire cellular space except the nucleus was occupied by dilated ER and a few megamitochondria. When we compared the dose-dependent effects of curcumin and DMC, we found that about fourfold higher concentration of curcumin was necessary to induce a similar extent of cellular vacuolation (Figure 3e). Accordingly, we examined whether DMC induced more effective induction of paraptosis is responsible for its stronger anticancer effects than those of curcumin. As paraptotic cell death is known to require protein synthesis, ${ }^{13,14}$ we first tested the effect of $\mathrm{CHX}$ on DMCinduced cell death. We found that pre-treatment of MDA-MB $435 S$ cells with $2 \mu \mathrm{M} \mathrm{CHX}$ almost completely blocked DMCinduced cell death and cellular vacuolation (Figure $4 a$ and b). In addition, treatment with $20 \mu \mathrm{M}$ DMC reduced the protein levels of Alix, an inhibitor of paraptosis, ${ }^{14}$ more rapidly and markedly than treatment with $40 \mu \mathrm{M}$ curcumin (Figure $4 \mathrm{c}$ ). As MAP kinases have been positively associated with paraptosis, ${ }^{3,14,19,23-26}$ we examined the functional significance of various MAP kinases in DMC-induced cell death and found that inhibition of the ERK pathway (using PD98059 or U0126) or the JNK pathway (using L-JNK Inhibitor 1 (L-JNKI)), but not inhibition of p38 (using SB203580), significantly inhibited DMCinduced cell death (Figure 4d). Western blot analysis showed that the activities of ERK and JNK were markedly and similarly increased by treatment with $20 \mu \mathrm{M}$ DMC or $40 \mu \mathrm{M}$ curcumin (Figure 4e).

Previously, we have shown that reactive oxygen species (ROS), in particular mitochondrial superoxide, and proteasomal inhibition critically contribute to the paraptosis induced by curcumin. ${ }^{3}$ Thus, we first attempted to examine the functional significance of ROS in DMC-induced cell death. We found that DMC-induced cell death was very effectively blocked by pretreatment with either $\mathrm{Mn}(\mathrm{III})$ tetrakis (4-benzoic acid) porphyrin chloride (MnTBAP; the MnSOD mimetic) or copper[II]diisopropyl salicylate (CuDIPS; the CuZnSOD mimetic), but not catalase (Figure 4f). FACS analysis using MitoSOX-Red showed that mitochondrial superoxide levels were time- and dose-dependently increased by DMC (Figure $4 \mathrm{~g}$ ), indicating that the increased mitochondrial superoxide has a critical role in DMCinduced cell death. Comparison of the mitochondrial superoxide levels in MDA-MB 435S cells treated with curcumin or DMC for $4 \mathrm{~h}$ revealed that DMC increased mitochondrial superoxide levels to a greater extent than curcumin (Figure 4h). Next, we tested whether DMC treatment could also inhibit proteasomal activity, as reflected by increased accumulation of ubiquitinated proteins. Treatment with $20 \mu \mathrm{M}$ DMC progressively increased the accumulation of protein-ubiquitin conjugates (Figure 4i), whereas pre-treatment with $\mathrm{CHX}$ completely blocked the accumulation of ubiquitinated proteins (Figure 4j). Collectively, our results show that paraptosis is a major mode of cell death by DMC in malignant breast cancer cells.

DMC more potently induces proteasomal inhibition and CHOP upregulation, compared with curcumin. Next, we examined whether the more potent anticancer effects of DMC over curcumin are associated with the increased inhibition of the proteasome and we found that the accumulation of ubiquitin conjugates in DMC-treated cells far exceeded that in curcumin-treated cells at each dose (Figure 5a). Immunocytochemistry of ubiquitin also showed that the expression levels of ubiquitin were more notably elevated in MDA-MB 4535 cells treated with $20 \mu \mathrm{M}$ DMC than those treated with $20 \mu \mathrm{M}$ curcumin (Figure 5b). Accordingly, we compared the effects of curcumin and DMC on cellular proteasome activities. The $20 \mathrm{~S}$ proteasome is a multicatalytic protease of the $26 \mathrm{~S}$ proteasome complex that has multiple peptidase activities, including chymotrypsin-like, trypsin-like and peptidylglutamyl peptide hydrolyzing-like (PGPH-like) activities. ${ }^{28}$ Consistent with the increased accumulation of protein-ubiquitin conjugates, treatment of MDA-MB 435S cells with DMC more effectively reduced chymotrypsin-like, trypsin-like and PGPH-like activities compared with the same doses of curcumin (Figure 5c). As synthetic fluorogenic substrates can be cleaved not only by the $20 \mathrm{~S}$ proteasome, but also by other proteases present in cell lysates, we investigated the direct effects of curcumin or DMC on the proteolytic activities of the purified 205 proteasome. Although both curcumin and DMC dosedependently inhibited the chymotrypsin-like, trypsin-like and PGPH-like hydrolytic activities of the purified 205 proteasome, the inhibitory effect of DMC was greater than that of 


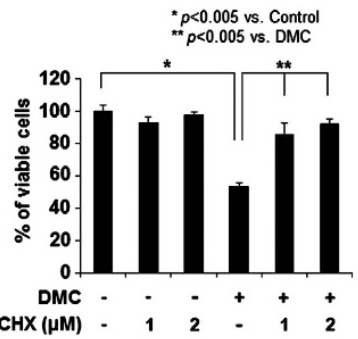

d
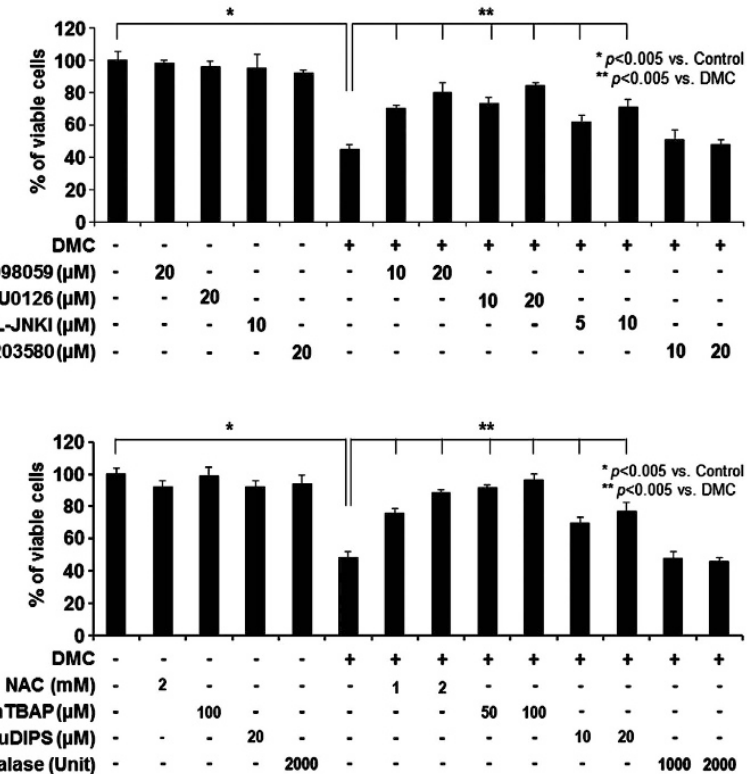

c

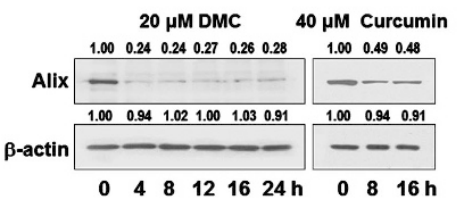

e

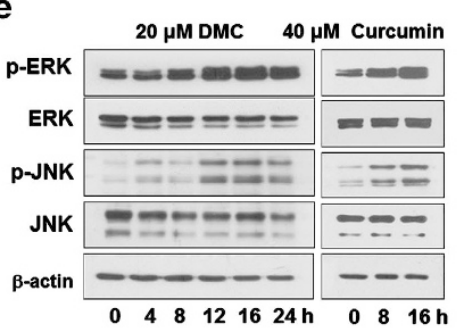

g

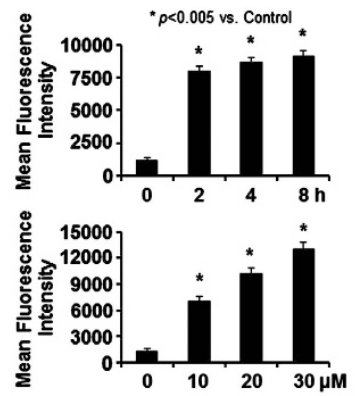

h

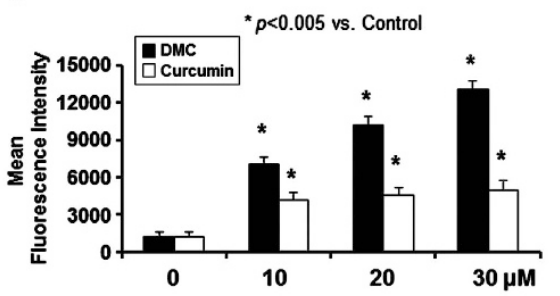

i

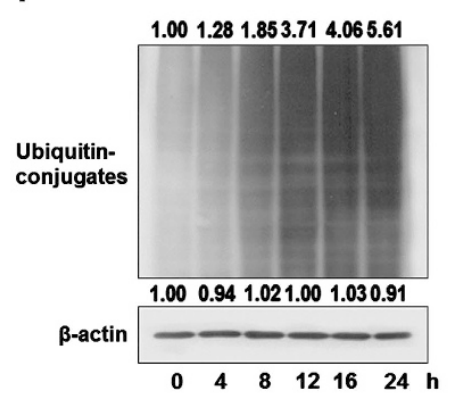

j

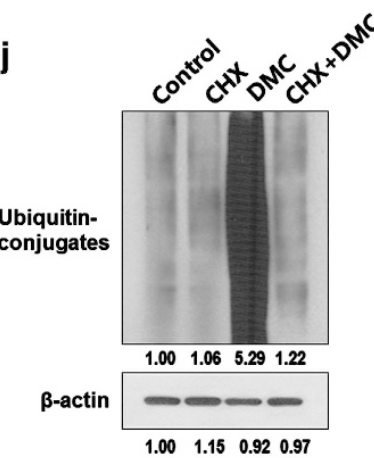

Figure 4 DMC activates paraptotic signals in malignant breast cancer cells. (a) MDA-MB $435 \mathrm{~S}$ cells were pre-treated with $\mathrm{CHX}$ at the indicated concentrations and further treated with $20 \mu \mathrm{M} \mathrm{DMC}$ for $24 \mathrm{~h}$. Cell viability was assessed using calcein-AM and EthD-1. (b) MDA-MB 435S cells were pre-treated with or without $2 \mu \mathrm{M}$ CHX and further treated with $20 \mu \mathrm{M} \mathrm{DMC}$ for $16 \mathrm{~h}$. Cellular morphologies after treatments were observed under a phase contrast microscope. Bar, $20 \mu \mathrm{m}$. (c) MDA-MB $435 \mathrm{~S}$ cells were treated with $20 \mu \mathrm{m} \mathrm{DMC}$ or $40 \mu \mathrm{m}$ curcumin for the indicated time points. Cell extracts were prepared for western blotting. Compared with control (untreated cells), the fold change of protein levels was determined. (d) MDA-MB 435S cells were pre-treated with the indicated specific inhibitors (PD98059, U0126, L-JNKI and SB203580) and further treated with $20 \mu \mathrm{m}$ DMC for $24 \mathrm{~h}$. Cell viability was assessed using calcein-AM and EthD-1. (e) MDA-MB $435 \mathrm{~S}$ cells treated with $20 \mu \mathrm{m}$ DMC or $40 \mu \mathrm{m}$ curcumin for the indicated time points were subjected to western blotting of the indicated proteins. Western blotting of $\beta$-actin was served as a loading control. (f) MDA-MB 435S cells were pre-treated with the indicated concentrations of various antioxidants and further treated with $20 \mu \mathrm{m}$ DMC for $24 \mathrm{~h}$. Cell viability was assessed using calcein-AM and EthD-1. (g) MDA-MB 435S cells were treated with $20 \mu \mathrm{m} \mathrm{DMC}$ for the indicated time periods or treated with DMC at the indicated concentrations for $4 \mathrm{~h}$ and stained with MitoSOX-Red. Treated and stained cells were processed for FACS analysis. (h) MDA-MB 435S cells were treated with DMC or curcumin at the indicated concentrations for $4 \mathrm{~h}$ and stained with MitoSOX Red. Treated and stained cells were processed for FACS analysis. (i) MDA-MB 435S cells treated with $20 \mu \mathrm{m}$ DMC for the indicated time points were subjected to western blotting of the indicated proteins. Western blotting of $\beta$-actin was served as a loading control. Compared with control (untreated cells), the fold change of protein levels was determined (j) MDA-MB 435S cells were pre-treated with or without $2 \mu \mathrm{m} \mathrm{CHX}$ and further treated with $20 \mu \mathrm{m} \mathrm{DMC}$ for $24 \mathrm{~h}$. Cell extracts were prepared for western blotting. Compared with control (untreated cells), the fold change of protein levels was determined

curcumin (Figure 5d). Taken together, these results suggest that, compared with curcumin, DMC exhibits a more potent inhibitory effect against proteasomal activity in malignant breast cancer cells. As proteasomal inhibition is known to induce ER stress, we examined the expression of ER stressassociated proteins in DMC-treated cells. The protein levels 
a

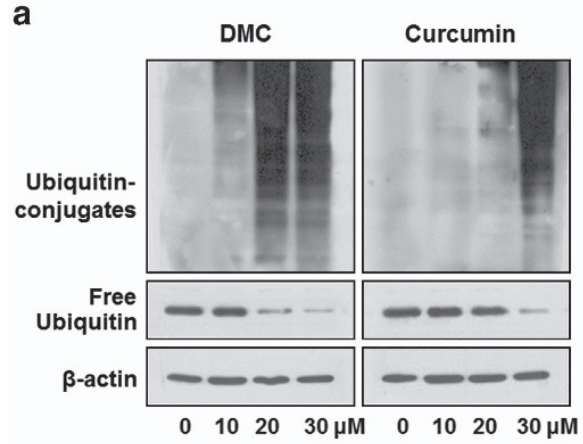

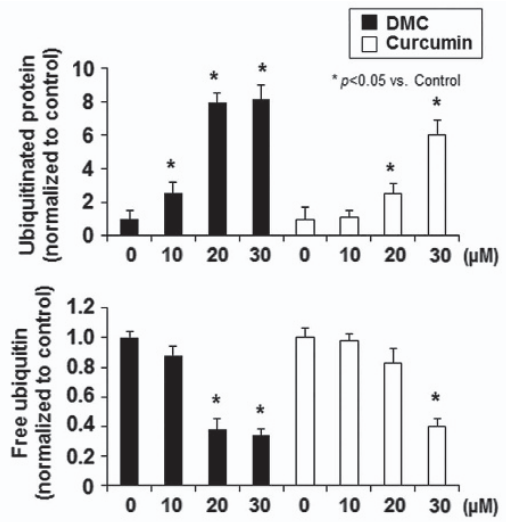

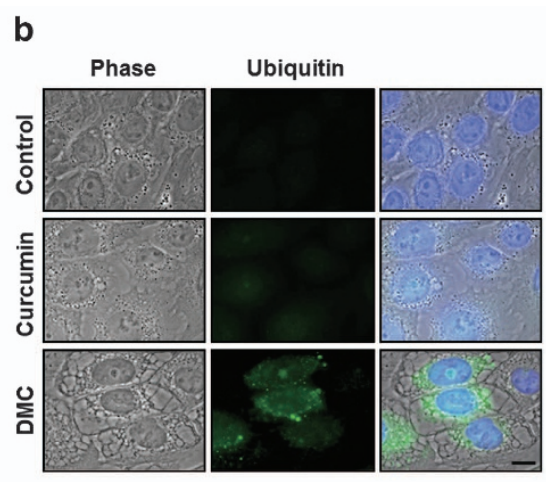

c
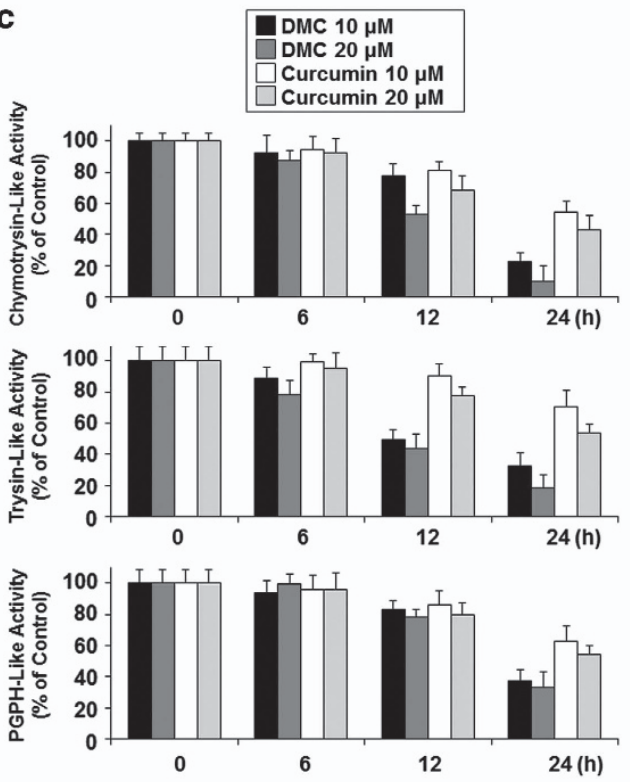

d
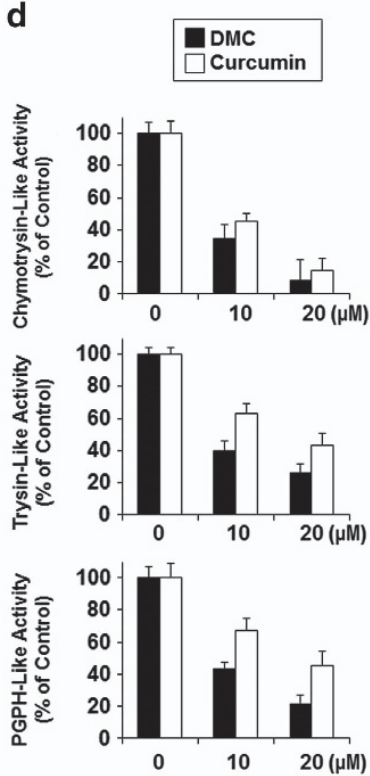

e

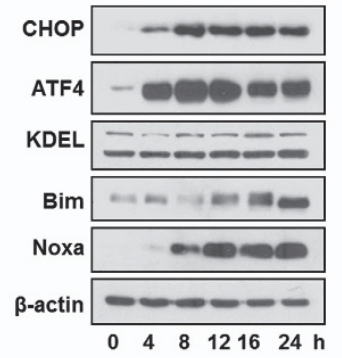

f

Figure 5 DMC more potently inhibits proteasomal activity than curcumin. (a) MDA-MB 435S cells treated with the indicated concentrations of DMC or curcumin for $24 \mathrm{~h}$ were subjected to western blotting. Protein poly-ubiquitination and free ubiquitin levels were examined by western blot analysis using an anti-ubiquitin antibody. $\beta$-Actin was examined to verify equal loading (left). Quantitation of the free ubiquitin and ubiquitinated protein levels. Compared with control (untreated cells), the fold change of protein levels was determined. Two independent western blots were normalized to $\beta$-actin band in the same sample (right). (b) MDA-MB $435 \mathrm{~S}$ cells treated with $20 \mu \mathrm{m}$ DMC or curcumin for $16 \mathrm{~h}$ were fixed, immunostained using anti-ubiquitin antibody (green) and counterstained with 4',6-diamidino-2-phenylindole (DAPI; blue). Processed cells were observed under the fluorescence and phase contrast microscope. Bar, $20 \mu \mathrm{m}$. (c) Cellular proteasomal activity in MDA-MB 435S cells treated with curcumin or DMC. MDA-MB $435 \mathrm{~S}$ cells were treated with curcumin or DMC at the indicated concentrations for 6,12 and $24 \mathrm{~h}$. The activities of 20S proteasome, including trypsin-like, chymotrypsin-like and PGPH-like activities, in the cell lysates were measured as described in Materials and Methods section. (d) The effects of curcumin or DMC on proteasome hydrolytic activities. Purified 20S proteasome $(70 \mathrm{ng})$ was incubated with the indicated concentrations of curcumin or DMC for $2 \mathrm{~h}$. Proteasomal trypsin-like, chymotrypsin-like and PGPH-like activities were measured as described in Materials and Methods section. (e) MDA-MB 435S cells treated with $20 \mu \mathrm{m}$ DMC for the indicated time points were subjected to western blotting of the indicated proteins. Western blotting of $\beta$-actin was served as a loading control. (f) MDA-MB $435 S$ cells treated with the indicated concentrations of DMC or curcumin for $24 \mathrm{~h}$ and cell extracts were prepared for western blotting of the indicated proteins

of activating transcription factor 4 (ATF4) and $\mathrm{CHOP}$ were markedly increased after $4 \mathrm{~h}$ of DMC treatment, whereas KDEL protein levels were not noticeably affected (Figure 5e). In addition, the protein levels of $\mathrm{Bim}^{29}$ and Noxa, ${ }^{29,30}$ which were reportedly associated with the cytotoxic effects of proteasome inhibitor (PI), were also progressively increased by DMC treatment. Curcumin and DMC had similar effects on Bim and KDEL, slightly increasing the protein levels of Bim but not noticeably altering the expression of KDEL (Figure 5f). Interestingly, however, DMC treatment markedly increased the protein levels of CHOP, ATF4 and Noxa at much lower doses compared with curcumin (Figure 5f).
CHOP upregulation critically contributes to DMCinduced paraptosis. As ATF4 was reported to confer resistance to proteasomal inhibition, ${ }^{31}$ we investigated whether CHOP or Noxa may have a critical role in DMCinduced cell death. Interestingly, small interfering RNA (siRNA)-mediated suppression of CHOP, but not that of Noxa, significantly inhibited DMC-induced cell death (Figure 6a), indicating that CHOP may be critically involved in DMC-induced paraptosis. Interestingly, CHOP knockdown did not affect the DMC-induced accumulation of polyubiquitinated proteins (Figure 6b), suggesting that the DMC-induced upregulation of CHOP may act downstream 


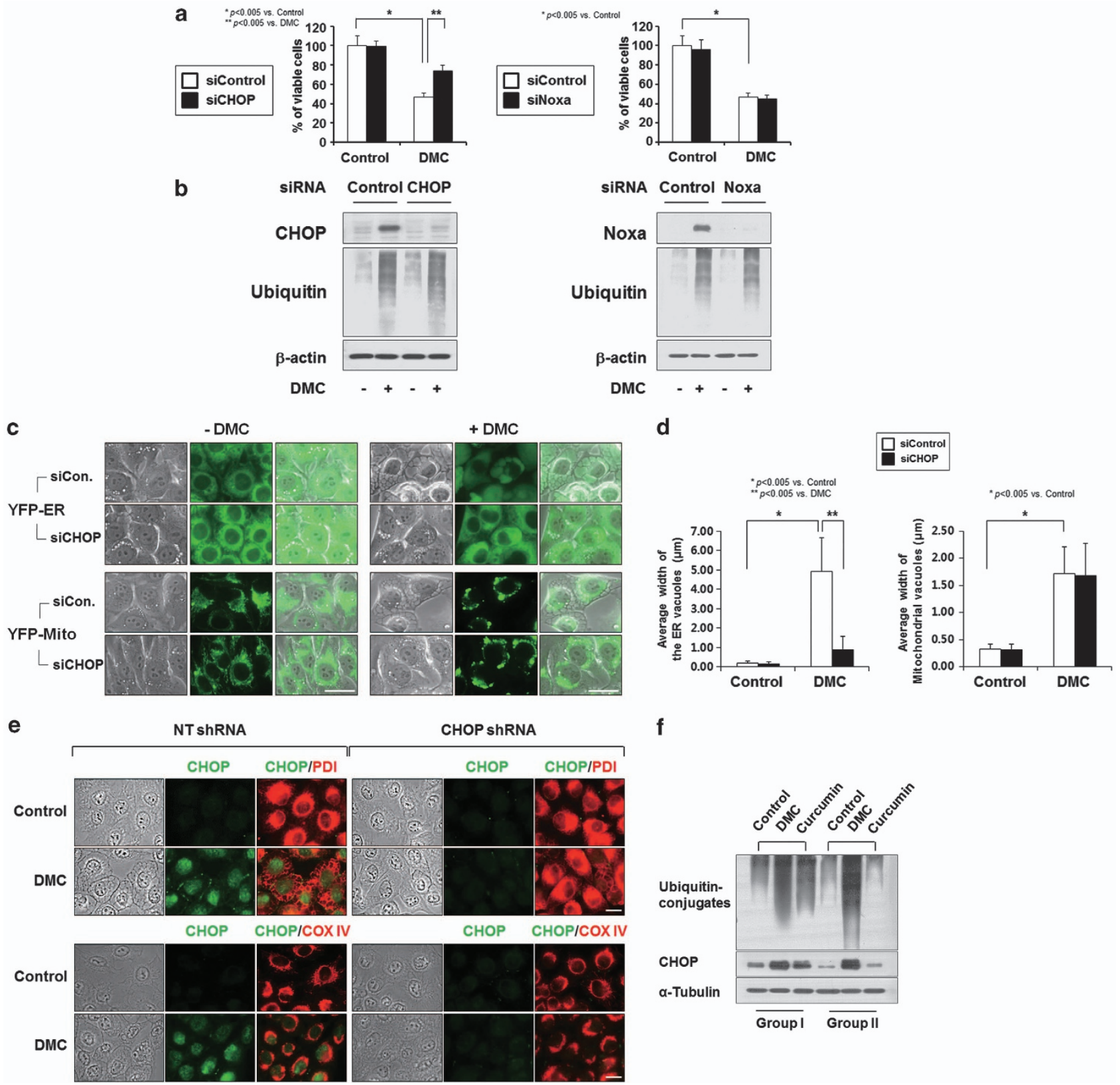

Figure 6 CHOP, but not Noxa, is critically involved in DMC-induced ER dilation and subsequent cell death. (a) MDA-MB 435S cells transfected with CHOP or Noxa siRNA were further treated with $20 \mu \mathrm{m} \mathrm{DMC}$ for $24 \mathrm{~h}$. Cellular viability was assessed using calcein-AM and EthD-1. (b) MDA-MB 435 cells were transfected with CHOP or Noxa siRNA and their knockdown was confirmed by western blotting of CHOP or Noxa. Effect of CHOP or Noxa knockdown on ubiquitinated proteins was examined by western blotting using anti-ubiquitin antibody. $\beta$-Actin expression was analyzed to confirm equal loading of the protein samples. (c) The sublines expressing the fluorescence selectively in ER (YFP-ER cells/435S) or mitochondria (YFP-Mito cells/435S) were transfected with CHOP siRNA and further treated with $20 \mu \mathrm{m} \mathrm{DMC} \mathrm{for} 16 \mathrm{~h}$. Cells were observed under a fluorescence microscope. Bars, $20 \mu \mathrm{m}$. (d) The changes in the widths of mitochondria-derived vacuoles and the ER-derived vacuoles by CHOP knockdown were quantitatively measured in YFP-Mito cells and YFP-ER cells treated with $20 \mu \mathrm{m} \mathrm{DMC} \mathrm{for} 16 \mathrm{~h}$ using AxioVision Rel. 4.8 software. CHOP knockdown significantly reduced the DMC-induced increase in the width of the ER. Results were repeated in three other experiments. In each experiment, 50 cells were scored as described in Materials and Methods section. (e) MDA-MB $435 \mathrm{~S}$ cells were infected with the lentivirus containing non-targeting (NT) shRNA or a CHOP-targeting shRNA (CHOP shRNA) and then treated with $20 \mu \mathrm{m}$ DMC for $16 \mathrm{~h}$. Treated cells were processed for immunocytochemistry of CHOP, PDI and COX IV. Bars, $20 \mu \mathrm{m}$. (f) Tumors in nude mice treated with DMC $(50 \mathrm{mg} / \mathrm{kg})$ or curcumin $(50 \mathrm{mg} / \mathrm{kg})$ were collected after 25 days of treatments and tissue extracts were prepared for western blotting using anti-ubiquitin and anti-CHOP antibody. Western blotting of $\alpha$-tubulin was examined to verify equal loading

of proteasomal impairment. Next, we used YFP-Mito and YFP-ER cells to investigate whether CHOP knockdown affected the DMC-induced dilation of mitochondria and/or the ER. The siRNA-mediated knockdown of CHOP markedly inhibited DMC-induced dilation of the ER, compared with its effect on DMC-induced mitochondrial dilation (Figures 6c, $6 \mathrm{~d}$, and Supplementary Figure 3). We further confirmed the effect of CHOP knockdown on DMC-induced dilation of mitochondria and the ER by immunocytochemistry of $\mathrm{CHOP}$, PDI and COX IV. In MDA-MB 435S cells infected with the 
lentivirus containing the non-targeting small hairpin RNA (shRNA) and further treated with DMC for $16 \mathrm{~h}, \mathrm{CHOP}$ was highly expressed at the nuclei (Figure 6e). At this condition, PDI was expressed at the boundary of dilated ER vacuoles, whereas COX IV was expressed within the dilated mitochondria. When we treated MDA-MB 435S cells with the lentivirus containing CHOP-targeting shRNA, DMC-induced cellular vacuolation was markedly attenuated. In addition, expression patterns of PDI following treatment with DMC were much similar to those of untreated cells, although mitochondriaexpressing COX IV appeared somewhat dilated. Taken together, these results suggest that DMC-induced proteasomal inhibition leads to the upregulation of $\mathrm{CHOP}$, critically contributing to dilation of the ER and paraptotic cell death. Accordingly, we examined whether DMC also inhibits proteasomal activity and increases CHOP protein levels more potently than curcumin in vivo. We found that DMC treatment more markedly increased the protein levels of poly-ubiquitinated proteins and $\mathrm{CHOP}$ compared with curcumin treatment in tumor specimens from nude mice harboring MDA-MB 435S cell xenografts (Figure 6f). Taken together, our results indicate that enhanced proteasome inhibition and $\mathrm{CHOP}$ upregulation may be responsible for the more potent anticancer effects of $\mathrm{DMC}$ on breast cancer cells in vitro and in vivo.

DMC does not inhibit proteasomal activity or cell viability in normal breast cells. Finally, we examined the effects of DMC on normal breast cells. Similar to curcumin, treatment of MCF-10A cells or human mammary epithelial cells (HMECs) with DMC up to $30 \mu \mathrm{M}$ did not induce any cell death (Figure 7a) or alterations in cell morphology (Figure 7b), suggesting that DMC is selectively cytotoxic to malignant breast cancer cells, while sparing normal breast cells. Furthermore, the accumulation of poly-ubiquitinated proteins and the upregulation of $\mathrm{CHOP}$, both of which were observed in DMC-treated MDA-MB $435 \mathrm{~S}$ cells, did not occur in HMECs (Figure 7c). Immunocytochemistry of ubiquitin and CHOP also showed that the expression levels of ubiquitin in the cytosol and nuclear CHOP were markedly increased in MDA-MB 435S cells, but not in HMECs, following treatment with $20 \mu \mathrm{M}$ DMC (Figure 7d). In addition, DMC-induced downregulation of Alix and upregulation of Noxa and Bim, which were shown in MDA-MB 435S cells, were not observed in HMECs (Figure 7e). Furthermore, flow cytometry using MitoSOXRed showed that DMC induced marked increase in mitochondrial superoxide levels, which were detected in MDA-MB 435S cells, were not observed in HMECs (Figure 7f). Taken together, our results indicate that DMC-induced activation of these paraptosis-associated signals, including proteasome inhibition (possibly leading to the upregulation of $\mathrm{CHOP},{ }^{32}$ $\mathrm{Noxa}^{29}$ and $\mathrm{Bim}^{29,30}$ ), Alix downregulation and superoxide generation, may contribute to its selective cytotoxicity to breast cancer cells, sparing normal cells.

\section{Discussion}

Despite the promise of curcumin as a chemopreventive ${ }^{33,34}$ and cancer-selective therapeutic agent, ${ }^{2-4}$ clinical trials have revealed that curcumin suffers from poor absorption, low bioavailability, low plasma levels, rapid metabolism and quick elimination from the body. ${ }^{35}$ Therefore, the potential clinical benefits of curcumin await improvements in its bioavailability. Many research groups have developed new synthetic analogs of curcumin; ${ }^{6-8}$ these include DMC, which shows potential as a potent chemotherapeutic agent. ${ }^{11,12,36}$ However, no previous study has assessed the comparative anticancer effects of DMC and curcumin against breast cancer in vitro and in vivo. Here, we report that $\mathrm{DMC}$ induces the death of various breast cancer cells, reduces the clonogenicities of MDA-MB 435S and MDA-MB 231 cells at much lower doses compared with curcumin, and more potently inhibited the growth of tumor xenografted with MDA-MB 435 S cells in vivo. In this study, we propose that the improved effects of DMC over curcumin in malignant breast cancer cells are due to more effective induction of paraptosis. Although the molecular basis of paraptosis is still not clearly understood, we conclude that DMC induces paraptosis based on the following morphological and biochemical characteristics: (a) DMC induces the swelling and fusion of mitochondria and the ER; (b) DMCinduced vacuolation and cell death is completely inhibited by $\mathrm{CHX}$; (c) the protein levels of Alix, which is a known inhibitor of paraptosis, ${ }^{14}$ are downregulated by DMC; (d) DMC increases mitochondrial superoxide levels and antioxidants significantly block DMC-induced cell death; and (e) DMC inhibits proteasomal activity. Furthermore, we show here for the first time that $\mathrm{CHOP}$ has a critical role in DMC-induced paraptosis, particularly in the context of ER dilation.

We recently showed that proteasomal dysfunction critically contributes to curcumin-induced paraptosis in malignant breast cancer cells. ${ }^{3}$ It has been reported that human cancer cells possess elevated proteasomal activity ${ }^{37}$ and are more sensitive to Pls than normal cells, ${ }^{38,39}$ indicating that the ubiquitin-proteasome pathway is a promising target for cancer therapy. Bortezomib, the first US Food and Drug Administration-approved $\mathrm{PI}$, is clinically used for the treatment of newly diagnosed multiple myeloma and mantle cell lymphoma 40,41 Giant ER-derived vacuoles have been increasingly recognized as indicating perturbation of the functional link between the ER and the proteasome. ${ }^{3,42}$ Failure of the proteasomal machinery leads to the accumulation of misfolded proteins in the ER and cytoplasm; this can overwhelm cells and lead to failure of the unfolded protein response and ER-associated degradation, both of which protect cells from proteotoxicity. ${ }^{27}$ Here, we found that DMC induced a greater accumulation of ubiquitinated proteins in MDA-MB 435S cells and a mouse xenograft tumor model, compared with curcumin. In addition, DMC more potently inhibited chymotrypsin-like, trypsin-like and PGPH-like activities (versus curcumin) in experiments using MDA-MB 4355 cell lysates or purified $20 S$ proteasomes. Collectively, these results indicate that $\mathrm{DMC}$ inhibits the proteasome more potently than curcumin, contributing to more effective induction of paraptosis. When we further examined the significance of various signals associated with PI-mediated ER stress and/ or toxicity, we found that DMC upregulated CHOP more potently than curcumin, and CHOP knockdown significantly attenuated DMC-induced cell death. Interestingly, DMCinduced ER dilation was almost completely blocked by CHOP knockdown, although DMC-induced dilation of mitochondria was not greatly affected by it. We found that curcumin-induced 

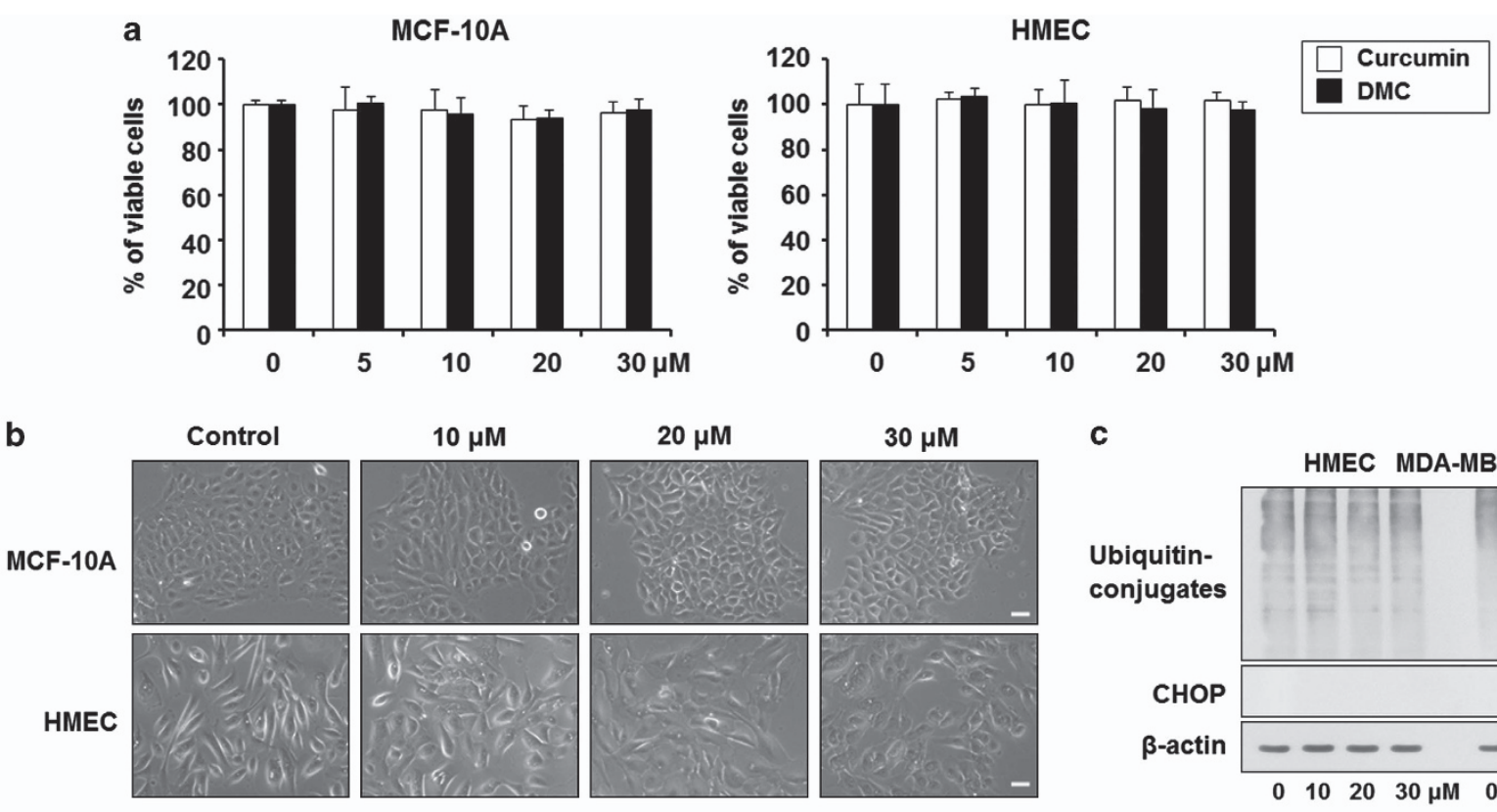

C

d

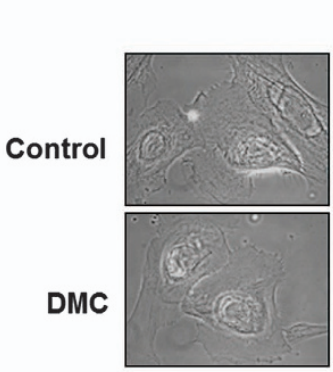

HMEC

Ubiquitin

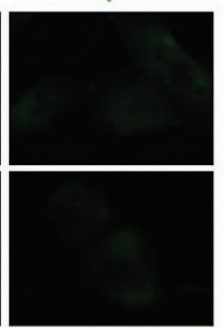

CHOP

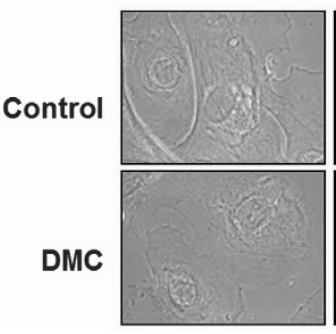

MDA-MB 435S

Ubiquitin
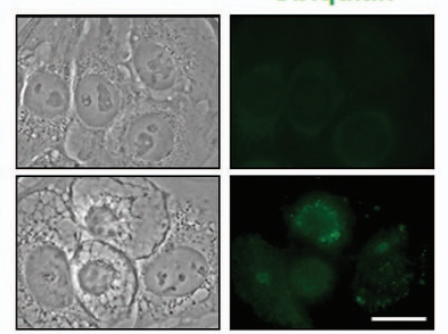

CHOP
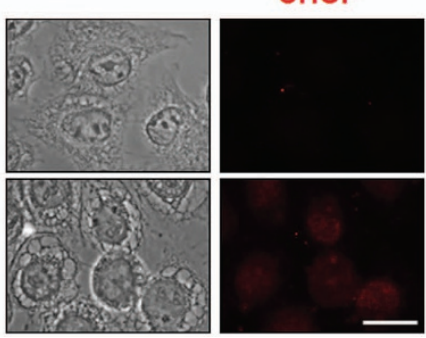

e

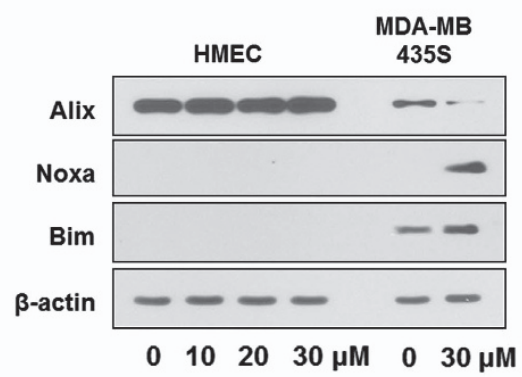

f

HMEC

MDA-MB 435S
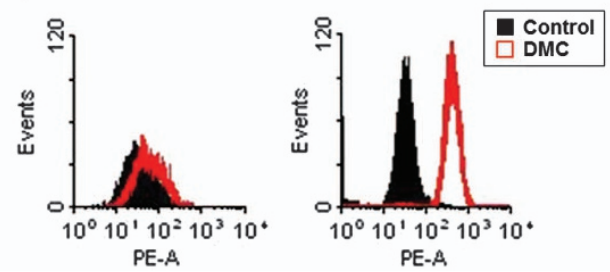

Figure 7 DMC does not induce cell death in normal breast cells. (a) MCF-10A or HMECs were treated with DMC or curcumin at the indicated concentrations for $24 \mathrm{~h}$. Cellular viability was assessed using calcein-AM and EthD-1. (b) MCF-10A cells or HMECs were treated with $20 \mu \mathrm{m}$ DMC for $16 \mathrm{~h}$ and observed under a phase contrast microscope. Bars, $20 \mu \mathrm{m}$. (c) HMECs or MDA-MB 435S cells were treated with DMC at the indicated concentrations for $24 \mathrm{~h}$. Cells extracts were prepared for western blotting of the indicated proteins. Western blotting of $\beta$-actin was served as a loading control. (d) HMECs or MDA-MB 435S cells were treated with $20 \mu \mathrm{m}$ DMC for $16 \mathrm{~h}$. Immunocytochemistry using anti-ubiquitin antibody or anti-CHOP antibody was performed and the representative images of cells are shown. Bars, $20 \mu \mathrm{m}$. (e) HMECs or MDA-MB $435 \mathrm{~S}$ cells were treated with DMC at the indicated concentrations for $24 \mathrm{~h}$. Cells extracts were prepared for western blotting of the indicated proteins. Western blotting of $\beta$-actin was served as a loading control. (f) HMECs or MDA-MB 435S cells were treated with or without $20 \mu \mathrm{m}$ DMC for $4 \mathrm{~h}$ and FACS analysis to detect mitochondrial superoxide using MitoSOX-Red was performed. The representative histograms are shown

ER dilation was also effectively blocked by $\mathrm{CHOP}$ knockdown (Supplementary Figure 4), suggesting that $\mathrm{CHOP}$ may have a critical role in paraptosis, particularly in the context of ER dilation. Further work is warranted to determine whether CHOP transcriptionally controls the expression of gene products responsible for DMC-induced dilation of the ER. Collectively, our results indicate that the upregulation of CHOP via DMC-induced proteasomal inhibition has a critical role in the induction of paraptosis, contributing to the more potent anticancer effects of DMC on malignant breast cancer cells, compared with curcumin.

Mechanistically, curcumin and DMC are both Michael acceptors ( $\alpha, \beta$-unsaturated $\beta$-diketo group) that can react with sulfhydryl groups. ${ }^{43}$ This can induce oxidative stress by altering the cellular redox balance, potentially elevating the levels of ROS. ${ }^{44}$ Kunwar et al. ${ }^{10}$ showed that, similar to 
curcumin, DMC increased the generation of ROS in tumor cells. When we compared the mitochondrial superoxide levels in MDA-MB 435S cells treated with curcumin or DMC for $4 \mathrm{~h}$, we found that DMC increased mitochondrial superoxide levels to a greater extent than curcumin (Figure 4h). The proteasome is known to be susceptible to oxidative modification and inactivation, ${ }^{45,46}$ so we presume that the severity of this DMCinduced oxidative stress may contribute to its more potent impairment of proteasomal activity. Furthermore, owing to cross-regulation, DMC-induced proteasomal inhibition may also further facilitate ROS induction by eliciting ER stress. ${ }^{47}$

Identification of effective paraptotic inducers and the elucidation of critical signals involved in this alternative cell death mode may facilitate the design of novel therapeutics against malignant cancer cells with defects in their apoptotic machineries. Therefore, this study may contribute to the fields of cancer therapy and cell death research by identifying DMC as a more effective paraptotic inducer than curcumin, while also clarifying the functional significance of proteasomal modulation and $\mathrm{CHOP}$ induction in paraptosis. To further confirm the clinical usefulness of DMC as a potential anticancer drug, future studies may be needed to examine its chemosensitizing effects for tumors and in vivo anticancer effects in a metastatic model.

\section{Materials and Methods}

Chemicals and antibodies. $\mathrm{N}$-acetyl cysteine, CUDIPS and polyethylene glycol catalase, CHX, 3-methyladenine (3-MA), bafilomycin A1, CQ, 4',6diamidino-2-phenylindole and crystal violet were purchased from Sigma-Aldrich (St. Louis, MO, USA). MitoSOX-Red, calcein acetoxymethyl ester (calcein-AM) and ethidium homodimer (EthD-1) were purchased from Molecular Probes (Carlsbad, CA, USA). MnTBAP, PD98059, U0126 and SB203580 were obtained from Calbiochem (San Diego, CA, USA). L-JNKI was purchased from Enzo Life Sciences, Inc. (Farmingdale, NY, USA). The following antibodies were used: monoclonal anti- $\beta$-actin (Sigma-Aldrich); anti-ubiquitin, ATG6 (BENC1) and ATF4 (Santa Cruz Biotechnologies, Santa Cruz, CA, USA); anti-KDEL (Stressgen, Ann Arbor, MI, USA); anti-Noxa and anti-Bim (BD Biosciences Pharmingen, San Jose, CA, USA); anti-phospho-ERK1/2, total ERK1/2, phospho-JNK, total JNK, ATG5, CHOP (GADD153), LC3B, and AIP-1/Alix (Cell Signaling, Beverly, MA, USA); horseradish peroxidase (HRP)-conjugated anti-rabbit lgG and HRP-conjugated anti-mouse IgG (Molecular Probes).

Synthesis of DMC. DMC was synthetically prepared as described ${ }^{48}$ at the College of Pharmacology, Wonkwang University (Iksan, Korea) and Department of Molecular Science and Technology, Ajou University (Suwon, Korea). The purity of compound, detected by HPLC, was $>90 \%$. All solvents used in this study were LC-MS grade and purchased from Sigma-Aldrich.

Cell culture. Human breast cancer cell lines MDA-MB 231, MDA-MB 435S, MCF-7, T-47D and MCF-10A were purchased from American Type Culture Collection (ATCC, Manassas, VA, USA) and they were cultured in DMEM supplemented with $10 \%$ fetal bovine serum and antibiotics (Gibco, Grand Island, NY, USA). Normal HMECs were purchased from Clonetics Corp. (San Diego, CA, USA) and maintained in mammary epithelial growth medium (MEGM; Clonetics Corp.) supplemented with bovine pituitary extract, insulin, human epidermal growth factor, hydrocortisone and antibiotics (Clonetics Corp.). The MCF-10A cells were cultured in the same MEGM additionally supplemented with $100 \mathrm{ng} / \mathrm{ml}$ cholera toxin (Calbiochem). Cell culture passage number $<5$ was used in this study. Curcumin ( $>94 \%$ purity, Sigma-Aldrich) was dissolved in dimethyl sulfoxide (DMSO) at a concentration of $40 \mathrm{mM}$ and stored in a dark colored bottle at $-20^{\circ} \mathrm{C}$. This stock solution was diluted to the required concentration when needed.

Measurement of cellular viability. Cell viability was assessed by double labeling of cells with $2 \mu \mathrm{M}$ calcein-AM and $4 \mu \mathrm{M}$ EthD-1. The calcein-positive live cells and EthD-1-positive dead cells were visualized using fluorescence microscope equipped with Zeiss filter set \#46 (excitation band pass, $500 / 20 \mathrm{~nm}$; emission band pass, $535 / 30 \mathrm{~nm}$ ) and \#20 (excitation band pass, $546 / 12 \mathrm{~nm}$; emission band pass, 575-640 nm) and counted (Zeiss, Oberkochen, Germany).

Clonogenic cell survival assay. MDA-MB $435 S$ cells were plated in six-well plates at a density of $1 \times 10^{3}$ cells per well in triplicate and treated with curcumin or DMC of different dose for various time; and then, cells were treated with fresh drug-free medium and incubated for additional 9 days. After 9 days, cells were fixed in cold-methanol and stained with $0.5 \%$ crystal violet. Image acquisition was conducted using a digital camera.

Knockdown experiments using siRNAs and shRNAs. The siRNA duplexes used in this study were purchased from Invitrogen (Carlsbad, CA, USA) and have the following sequences: CHOP (NCBI accession no. NM_004083, 5'-GAGCUCUGAUUGACCGAAUGGUGAA-3'); Noxa (Santa Cruz Biotechnologies, cat. no. sc-37305); LC3B (Santa Cruz Biotechonlogies, cat. no. sc-43390). BLOCK-iT Fluorescent Oligo (Invitrogen) or Negative Universal Control (Invitrogen) was used as the control. After annealing of the pairs of siRNA oligos, cells in 24-well plates were transfected with $40 \mathrm{nM}$ siRNA oligonucleotides using Lipofectamine 2000 regent (Invitrogen), according to the manufacturer's instructions. For the knockdown experiments using CHOP-targeting shRNA, HEK293TN cells were transfected with the plasmid containing the non-targeting shRNA (SHCO02V, Sigma-Aldrich) or the plasmid containing CHOP-targeting shRNA (TRCN0000364328, Sigma-Aldrich), together with pMD2.G (the envelope plasmid) and pPsAX2.0 plasmid (the packaging plasmid), using TransIT-2020 transfection reagents (Mirus Bio LLC, Madison, WI, USA) according to the manufacturer's instructions. After $48 \mathrm{~h}$ of lentiviral particle production, MDA-MB $435 \mathrm{~S}$ cells were infected with the filtered lentiviral medium (derived from HEK293TN cultures) supplemented with $4 \mu \mathrm{g} / \mathrm{ml}$ polybrene.

Establishment of the stable cell lines expressing the fluorescence specifically in mitochondria or ER. To establish the stable cell lines expressing the fluorescence specifically in mitochondria or ER, MDA-MB $435 S$ cells were transfected with the pEYFP-Mito or pEYFP-ER vector (Clontech, Mountain, CA, USA). Stable cell lines expressing pEYFP-Mito or pEYFP-ER (YFP-Mito or YFP-ER) were selected with fresh medium containing $500 \mu \mathrm{g} / \mathrm{ml}$ G418 (Calbiochem). To quantitatively measure the dilation of mitochondria and the ER induced by DMC, we analyzed the average width of the vacuoles originated from mitochondria and the ER in YFP-Mito and YFP-ER cells using AxioVision Rel. 4.8 software (Zeiss). More than 200 clearly identifiable vacuoles derived from mitochondria in 50 YFP-Mito cells and $>200$ clearly identifiable vacuoles derived from the ER in 50 YFP-ER cells per experiment, randomly selected, were measured in three independent experiments.

Measurement of mitochondrial superoxide production. To measure mitochondrial superoxide production, cells were loaded with $2.5 \mu \mathrm{M}$ MitoSOX-Red for $20 \mathrm{~min}$ in the dark, washed with Hank's balanced salt solution (HBSS) with $\mathrm{Ca}^{2+}$ and $\mathrm{Mg}^{2+}$, and further processed for flow cytometry.

Western blotting. Cells were washed in PBS and lysed in boiling sodium dodecyl sulfate/polyacrylamide gel electrophoresis (SDS-PAGE) sample buffer (62.5 mM Tris (pH6.8), 1\% SDS, 10\% glycerol and 5\% $\beta$-mercaptoethanol). The lysates were boiled for $5 \mathrm{~min}$, separated by SDS-PAGE and transferred to an Immobilon membrane (Millipore, Bredford, MA, USA). After blocking nonspecific binding sites for $1 \mathrm{~h}$ by $5 \%$ skim milk, membranes were incubated for $2 \mathrm{~h}$ with specific Abs. Membranes were then washed three times with TBST and incubated further for $1 \mathrm{~h}$ with HRP-conjugated anti-rabbit, mouse or goat antibody. Visualization of protein bands was accomplished using ECL (Amersham Pharmacia Biotech, Piscataway, NJ, USA). The protein band intensity was quantified by densitometric analysis using the NIH ImageJ program (National Institutes of Health, Bethesda, MD, USA). The representative results from at least three independent experiments are shown.

Immunocytochemistry. After treatments, cell were fixed with acetone/ methanol (1:1) for $5 \mathrm{~min}$ at $-20^{\circ} \mathrm{C}$ and blocking in $5 \%$ BSA in PBS for $30 \mathrm{~min}$. Fixed cells were incubated overnight at $4{ }^{\circ} \mathrm{C}$ with primary antibody (anti-ubiquitin (1:500, mouse; Santa Cruz Biotechnologies), anti-CHOP (1:500, mouse; Cell Signaling), anti-COX IV (1:500, rabbit; GeneTex, Irvine, CA, USA) and anti-PDI $(1: 500$, rabbit; Stressgen)) diluted in PBS and then washed three times in PBS 
and incubated for $1 \mathrm{~h}$ at room temperature with anti-rabbit or anti-mouse Alexa Fluor 488 or 594 (1:500, Molecular Probes). Slides were mounted with ProLong Gold antifade mounting reagent (Molecular Probes) and cell staining was visualized with a fluorescence microscope using Zeiss filter sets \#46 and \#64HE (excitation band pass, 598/25 nm; emission band pass, $647 / 70 \mathrm{~nm}$ ).

Transmission electron microscopy. Cells were prefixed in Karnovsky's solution ( $1 \%$ paraformaldehyde, $2 \%$ glutaraldehyde, $2 \mathrm{mM}$ calcium chloride, $0.1 \mathrm{M}$ cacodylate buffer, $\mathrm{pH} 7.4$ ) for $2 \mathrm{~h}$ and washed with cacodylate buffer. Post-fixing was carried out in $1 \%$ osmium tetroxide and $1.5 \%$ potassium ferrocyanide for $1 \mathrm{~h}$. After dehydration with 50-100\% alcohol, the cells were embedded in Poly/Bed 812 resin (Pelco, Redding, CA, USA) and polymerized, and observed under electron microscope (EM 902A, Zeiss).

$20 \mathrm{~S}$ proteasome activity assay in intact cells. MDA-MB $435 \mathrm{~S}$ cells cultured in 96-well plates $\left(1 \times 10^{4}\right.$ cells per well) were treated for various time points with different concentrations of curcumin or DMC. After the additional $2 \mathrm{~h}$ incubation with the specific fluorogenic peptide substrates, production of hydrolyzed AMC groups was measured using a fluorometer (SPECTRAmax Gemini EM, Molecular Devices, Union City, CA, USA) with 355-nm excitation and 465-nm emission wavelengths. The fluorogenic substrates Bz-Val-Gly-Arg-AMC, Z-Leu-Leu-Glu-AMC (Calbiochem) and Suc-Leu-Leu-Val-Tyr-AMC (Cayman Chemical, Ann Arbor, MI, USA) were used to determine the 20S proteasome trypsin-like, chymotrypsin-like and PGPH-like activities, respectively.

Inhibition of purified $20 \mathrm{~S}$ proteasome activity. Purified rabbit $20 \mathrm{~S}$ proteasome $(70 \mathrm{ng})$ was incubated with DMC or curcumin at different concentrations or the solvent DMSO in the assay buffer $(20 \mathrm{mM}$ Tris- $\mathrm{HCl}$, $\mathrm{pH}$ 7.5) for $30 \mathrm{~min}$ at $37^{\circ} \mathrm{C}$ before synthetic fluorogenic substrates were added. The fluorogenic peptide substrates (Suc-Leu-Leu-Val-Tyr-AMC, Bz-Val-Gly-Arg-AMC and Z-Leu-Leu-Glu-AMC) in $100 \mu$ lassay buffer in the presence of DMC or curcumin at different concentrations or the solvent DMSO for $2 \mathrm{~h}$ at $37^{\circ} \mathrm{C}$, followed by measurement of hydrolysis of the fluorogenic substrates using a fluorometer with 355-nm excitation and 460-nm emission wavelengths.

MDA-MB 435 cell tumor xenograft in mice. Six- to 8-week-old female athymic nude mice (Balb/c nu/nu) were obtained from Orient Bio. (Seoul, South Korea) and kept in the animal facility at least 1 week before starting the experiments. All experiments involving animals have been reviewed and approved by the licensing and ethical committee of the ethical committee of Ajou University School of Medicine. Human breast cancer MDA-MB 435S cells $\left(5 \times 10^{6}\right)$ suspended in $100 \mu$ l of HBSS (without $\mathrm{Ca}^{2+}$ and $\mathrm{Mg}^{2+}$ ) were subcutaneously injected into the right flank of each mouse. When tumors reached sizes of $\sim 80 \mathrm{~mm}^{3}$, the mice were then randomly grouped and received $100 \mu \mathrm{l}$ vehicle (filter-sterilized PBS containing $0.25 \%$ DMSO), curcumin or DMC of 25 or $50 \mathrm{mg} / \mathrm{kg}$ by intraperitoneal injections at the intervals of 2 days for 25 days. Tumor size was measured every 2 days using calipers and their volumes were calculated according to a standard formula: (width ${ }^{2} \times$ length)/2. At the end of the treatment, tumor tissues from the treated mice were collected for western blot to detect ubiquitinated proteins and $\mathrm{CHOP}$.

In vivo tumor imaging. Following the establishment of MDA-MB $435 \mathrm{~S}$ cells that stably expressed luciferase (MDA-MB 435S/Luc), $2 \times 10^{6}$ MDA-MB 435S/Luc cells were injected into the left thighs of 6-8 weeks old male nude mice (Orient Bio.). Two weeks after cell injection, mice were randomized into groups ( $n=5$ animals per group) and received $100 \mu \mathrm{l}$ of vehicle, $50 \mathrm{mg} / \mathrm{kg}$ curcumin or DMC by intraperitoneal injections at intervals of 2 days for 20 days. For bioluminescence imaging, mice were injected intraperitoneally with D-luciferin $(100 \mathrm{mg} / \mathrm{kg}$ body weight in $0.1 \mathrm{ml}$ of sterile PBS). Thirteen minutes after injection with $D$-luciferin, the mice were anesthetized with isoflurane and imaged using IVISTM 100 (Caliper Life Sciences, Hopkinton, MA, USA) and various exposure times ( $1 \mathrm{~s}$ to $2 \mathrm{~min}$ ) for image optimization. The results were analyzed with the Live Image 2.20 software package (Xenogen Corp, Alameda, CA, USA). The signal intensity was quantified as the sum of all detected photon counts within the region of interest (ROI) after subtraction of background luminescence measured from the corresponding ROI of control mice.

Statistical analysis. All data were presented as mean \pm S.D. from at least three separate experiments. Student's $t$-test was applied to evaluate the differences between treated and control groups with cell viability. Data from multiple groups were analyzed by one-way ANOVA, followed by Bonferroni multiple comparison test. For all the tests, the level of significance was values of $P<0.05$.

\section{Conflict of Interest}

The authors declare no conflict of interest.

Acknowledgements. This research was supported by the National Research Foundation of Korea (NRF) grant funded by the Korean government (MSIP) (No. 2011-0018141 (Mid-Career Researcher Program)).

\section{Author contributions}

MJY and KSC designed research; MJY, YJK, JAL, IYK, YL, JHP, BYL, HSK, S-AK, A-RY, E-YK, and IAK performed all experiments; MJY and KSC wrote the paper; MAK, C-OY, KL and KSC analyzed data.

1. Smigal C, Jemal A, Ward E, Cokkinides V, Smith R, Howe HL et al. Trends in breast cancer by race and ethnicity: update 2006. CA Cancer J Clin 2006; 56: 168-183.

2. López-Lázaro M. Anticancer and carcinogenic properties of curcumin: considerations for its clinical development as a cancer chemopreventive and chemotherapeutic agent. Mol Nutr Food Res 2008; 52: S103-S127.

3. Yoon MJ, Kim EH, Lim JH, Kwon TK, Choi KS. Superoxide anion and proteasomal dysfunction contribute to curcumin-induced paraptosis of malignant breast cancer cells. Free Radic Biol Med 2010; 48: 713-726.

4. Syng-Ai C, Kumari AL, Khar A. Effect of curcumin on normal and tumor cells: role of glutathione and bcl-2. Mol Cancer Ther 2004; 3: 1101-1108.

5. Anand P, Kunnumakkara AB, Newman RA, Aggarwal BB. Bioavailability of curcumin: problems and promises. Mol Pharm 2007; 4: 807-818.

6. Adams BK, Cai J, Armstrong J, Herold M, Lu YJ, Sun A et al. EF24, a novel synthetic curcumin analog, induces apoptosis in cancer cells via a redox dependent mechanism. Anticancer Drugs 2005; 16: 263-275.

7. Anand P, Thomas SG, Kunnumakkara AB, Sundaram C, Harikumar KB, Sung B et al. Biological activities of curcumin and its analogues (Congeners) made by man and mother nature. Biochem Pharmacol 2008; 76: 1590-1611.

8. Padhye S, Yang H, Jamadar A, Cui QC, Chavan D, Dominiak K et al. New difluoro Knoevenagel condensates of curcumin, their Schiff bases and copper complexes as proteasome inhibitors and apoptosis inducers in cancer cells. Pharm Res 2009; 26: $1874-1880$

9. Priyadarsini KI, Maity DK, Naik GH, Kumar MS, Unnikrishnan MK, Satav JG et al. Role of phenolic $\mathrm{O}-\mathrm{H}$ and methylene hydrogen on the free radical reactions and antioxidant activity of curcumin. Free Radic Biol Med 2003; 35: 475-484

10. Kunwar A, Barik A, Sandur SK, Indira Priyadarsini K. Differential antioxidant/pro-oxidant activity of dimethoxycurcumin, a synthetic analogue of curcumin. Free Radic Res 2011; 45: 959-965.

11. Tamvakopoulos C, Dimas K, Sofianos ZD, Hatziantoniou S, Han Z, Liu ZL et al. Metabolism and anticancer activity of the curcumin analogue, dimethoxycurcumin. Clin Cancer Res 2007; 13: 1269-1277.

12. Lee JW, Hong HM, Kwon DD, Pae HO, Jeong HJ. Dimethoxycurcumin a structural analogue of curcumin, induces apoptosis in human renal carcinoma caki cells through the production of reactive oxygen species, the release of cytochrome $\mathrm{C}$, and the activation of caspase-3. Korean J Urol 2010; 51: 870-878.

13. Sperandio S, de Belle I, Bredesen DE. An alternative, nonapoptotic form of programmed cell death. Proc Natl Acad Sci USA 2000; 97: 14376-14381.

14. Sperandio S, Poksay K, de Belle I, Lafuente MJ, Liu B, Nasir J et al. Paraptosis: mediation by MAP kinases and inhibition by AIP-1/Alix. Cell Death Differ 2004; 11: 1066-1075.

15. Wasik AM, Almestrand S, Wang X, Hultenby K, Dackland ÅL, Andersson P et al. WIN55,212-2 induces cytoplasmic vacuolation in apoptosis-resistant MCL cells. Cell Death Dis 2011; 2: e225.

16. Bredesen DE, Rao RV, Mehlen P. Cell death in the nervous system. Nature 2006; 443 796-802.

17. Pais V, Danaila $L$, Pais E. Ultrastructural patterns of the activated cell death programs in the human brain. Ultrastruct Pathol 2013; 37: 110-120.

18. Chen TS, Wang XP, Sun L, Wang LX, Xing D, Mok M. Taxol induces caspase-independent cytoplasmic vacuolization and cell death through endoplasmic reticulum (ER) swelling in ASTC-a-1 cells. Cancer Lett 2008; 270: 164-172.

19. Yoon MJ, Kim EH, Kwon TK, Park SA, Choi KS. Simultaneous mitochondrial $\mathrm{Ca}(2+)$ overload and proteasomal inhibition are responsible for the induction of paraptosis in malignant breast cancer cells. Cancer Lett 2012; 324: 197-209.

20. Bury M, Girault A, Mégalizzi V, Spiegl-Kreinecker S, Mathieu V, Berger W et al. Ophiobolin A induces paraptosis-like cell death in human glioblastoma cells by decreasing $\mathrm{BKCa}$ channel activity. Cell Death Dis 2013; 4: e561. 
21. Valamanesh F, Torriglia A, Savoldelli M, Gandolphe C, Jeanny JC, BenEzra D et al. Glucocorticoids induce retinal toxicity through mechanisms mainly associated with paraptosis. Mol Vis 2007; 13: 1746-1757.

22. Fombonne J, Padrón L, Enjalbert A, Krantic S, Torriglia A. A novel paraptosis pathway involving LEI/L-DNasell for EGF-induced cell death in somato-lactotrope pituitary cells. Apoptosis 2006; 11: 367-375.

23. Asare N, Landvik NE, Lagadic-Gossmann D, Rissel M, Tekpli X, Ask K et al. 1-Nitropyrene (1-NP) induces apoptosis and apparently a non-apoptotic programmed cell death (paraptosis) in Hepa1c1c7 cells. Toxicol Appl Pharmacol 2008; 230: 175-186.

24. Sun $Q$, Chen $T$, Wang $X$, Wei $X$. Taxol induces paraptosis independent of both protein synthesis and MAPK pathway. J Cell Physiol 2010; 222: 421-432.

25. Wang WB, Feng LX, Yue QX, Wu WY, Guan SH, Jiang BH et al. Paraptosis accompanied by autophagy and apoptosis was induced by celastrol, a natural compound with influence on proteasome, ER stress and Hsp90. J Cell Physiol 2012; 227: 2196-2206.

26. Korsnes MS, Espenes A, Hetland DL, Hermansen LC. Paraptosis-like cell death induced by yessotoxin. Toxicol In Vitro 2011; 25: 1764-1770.

27. Kar R, Singha PK, Venkatachalam MA, Saikumar P. A novel role for MAP1 LC3 in nonautophagic cytoplasmic vacuolation death of cancer cells. Oncogene 2009; 28 : 2556-2568.

28. Adams J. The proteasome: structure, function, and role in the cell. Cancer Treat Rev 2003; 1: $3-9$.

29. Fennell DA, Chacko A, Mutti L. BCL-2 family regulation by the $20 \mathrm{~S}$ proteasome inhibitor bortezomib. Oncogene 2008; 27: 1189-1197.

30. Chen S, Blank JL, Peters T, Liu XJ, Rappoli DM, Pickard MD et al. Genome-wide siRNA screen for modulators of cell death induced by proteasome inhibitor bortezomib. Cancer Res 2010; 70: 4318-4326

31. Milani M, Rzymski T, Mellor HR, Pike L, Bottini A, Generali D et al. The role of ATF4 stabilization and autophagy in resistance of breast cancer cells treated with bortezomib. Cancer Res 2009; 60: 4415-4423.

32. Lee AH, Iwakoshi NN, Anderson KC, Glimcher LH. Proteasome inhibitors disrupt the unfolded protein response in myeloma cells. Proc Natl Acad Sci USA 2003; 100: 9946-9951.

33. Gescher AJ, Sharma RA, Steward WP. Cancer chemoprevention by dietary constituents: a tale of failure and promise. Lancet Oncol 2001; 2: 371-379.

34. Rao CV, Rivenson A, Simi B, Reddy BS. Chemoprevention of colon carcinogenesis by dietary curcumin, a naturally occurring plant phenolic compound. Cancer Res 1995; 55: 259-266.

35. Shehzad A, Khan S, Shehzad O, Lee YS. Curcumin therapeutic promises and bioavailability in colorectal cancer. Drugs Today (Barc) 2010; 46: 523-532.

36. Ohtsu H, Xiao Z, Ishida J, Nagai M, Wang HK, Itokawa H et al. Antitumor agents. 217. Curcumin analogues as novel androgen receptor antagonists with potential as antiprostate cancer agents. J Med Chem 2002; 4: 5037-5042.
37. Chen D, Dou QP. The ubiquitin-proteasome system as a prospective molecular target for cancer treatment and prevention. Curr Protein Pept Sci 2010; 11: 459-470.

38. Bazzaro M, Lee MK, Zoso A, Stirling WL, Santillan A, Shih leM et al. Ubiquitin-proteasome system stress sensitizes ovarian cancer to proteasome inhibitor-induced apoptosis. Cancer Res 2006; 66: 3754-3763.

39. Yang $\mathrm{H}$, Landis-Piwowar KR, Chen D, Milacic V, Dou QP. Natural compounds with proteasome inhibitory activity for cancer prevention and treatment. Curr Protein Pept Sci 2008; 9: 227-239.

40. Kane RC, Bross PF, Farrell AT, Pazdur R. Velcade: U.S. FDA approval for the treatment of multiple myeloma progressing on prior therapy. Oncologist 2003; 8: 508-513.

41. Kane RC, Dagher R, Farrell A, Ko CW, Sridhara R, Justice R et al. Bortezomib for the treatment of mantle cell lymphoma. Clin Cancer Res 2007; 13: 5291-5294.

42. Mimnaugh EG, Xu W, Vos M, Yuan X, Neckers L. Endoplasmic reticulum vacuolization and valosin-containing protein relocalization result from simultaneous hsp90 inhibition by geldanamycin and proteasome inhibition by velcade. Mol Cancer Res 2006; 4: 667-681.

43. Dinkova-Kostova AT, Massiah MA, Bozak RE, Hicks RJ, Talalay P. Potency of Michael reaction acceptors as inducers of enzymes that protect against carcinogenesis depends on their reactivity with sulfhydryl groups. Proc Natl Acad Sci USA 2001; 98 3404-3409.

44. Raja SM, Clubb RJ, Ortega-Cava C, Williams SH, Bailey TA, Duan L et al. Anticancer activity of Celastrol in combination with ErbB2-targeted therapeutics for treatment of ErbB2-overexpressing breast cancers. Cancer Biol Ther 2011; 11: 263-276.

45. Ding $Q$, Keller JN. Proteasome inhibition in oxidative stress neurotoxicity: implications for heat shock proteins. J Neurochem 2001; 77: 1010-1017.

46. Okada K, Wangpoengtrakul C, Osawa T, Toyokuni S, Tanaka K, Uchida K. 4-Hydroxy2-nonenal-mediated impairment of intracellular proteolysis during oxidative stress. Identification of proteasomes as target molecules. J Biol Chem 1999; 274: 23787-23793.

47. Malhotra JD, Kaufman RJ. Endoplasmic reticulum stress and oxidative stress: a vicious cycle or a double edged sword? Antioxid Redox Signal 2007; 9: 2277-2293.

48. Chen WF, Deng SL, Zhou B, Yang L, Liu ZL. Curcumin and its analogues as potent inhibitors of low density lipoprotein oxidation: $\mathrm{H}$-atom abstraction from the phenolic groups and possible involvement of the 4-hydroxy-3-methoxyphenyl groups. Free Radic Biol Med 2006; 40: 526-535.

(1) $(\Theta)$ Cell Death and Disease is an open-access journal (c) published by Nature Publishing Group. This work is licensed under a Creative Commons Attribution-NonCommercialNoDerivs 3.0 Unported License. To view a copy of this license, visit http://creativecommons.org/licenses/by-nc-nd/3.0/

Supplementary Information accompanies this paper on Cell Death and Disease website (http://www.nature.com/cddis) 